\title{
Tight sandstone gas accumulation mechanism and development models
}

\author{
Zhen-Xue Jiang ${ }^{1,2} \cdot{\text { Zhuo } \mathrm{Li}^{1,2} \cdot \text { Feng } \mathrm{Li}^{1,2} \cdot \text { Xiong-Qi Pang }}^{1,3} \cdot$ Wei Yang ${ }^{1,2}$. \\ Luo-Fu Liu $^{1,3} \cdot$ Fu-Jie Jiang ${ }^{1,3}$
}

Received: 11 May 2015/Published online: 19 October 2015

(c) The Author(s) 2015. This article is published with open access at Springerlink.com

\begin{abstract}
Tight sandstone gas serves as an important unconventional hydrocarbon resource, and outstanding results have been obtained through its discovery both in China and abroad given its great resource potential. However, heated debates and gaps still remain regarding classification standards of tight sandstone gas, and critical controlling factors, accumulation mechanisms, and development modes of tight sandstone reservoirs are not determined. Tight sandstone gas reservoirs in China are generally characterized by tight strata, widespread distribution areas, coal strata supplying gas, complex gas-water relations, and abnormally low gas reservoir pressure. Water and gas reversal patterns have been detected via glass tube and quartz sand modeling, and the presence of critical geological conditions without buoyancy-driven mechanisms can thus be assumed. According to the timing of gas charging and reservoir tightening phases, the following three tight sandstone gas reservoir types have been
\end{abstract}

Zhen-Xue Jiang

jiangzx@cup.edu.cn

Zhuo Li

zhuo.li@cup.edu.cn

1 State Key Laboratory of Petroleum Resources and Prospecting, China University of Petroleum, Beijing 102249, China

2 Unconventional Natural Gas Institute, China University of Petroleum, Beijing 102249, China

3 College of Geosciences, China University of Petroleum, Beijing 102249, China

Edited by Jie Hao identified: (a) "accumulation-densification" (AD), or the conventional tight type, (b) "densification-accumulation" (DA), or the deep tight type, and (c) the composite tight type. For the $\mathrm{AD}$ type, gas charging occurs prior to reservoir densification, accumulating in higher positions under buoyancy-controlled mechanisms with critical controlling factors such as source kitchens (S), regional overlaying cap rocks (C), gas reservoirs, (D) and low fluid potential areas (P). For the DA type, reservoir densification prior to the gas charging period (GCP) leads to accumulation in depressions and slopes largely due to hydrocarbon expansive forces without buoyancy, and critical controlling factors are effective source rocks (S), widely distributed reservoirs (D), stable tectonic settings (W) and universal densification of reservoirs (L). The composite type includes features of the AD type and DA type, and before and after reservoir densification period (RDP), gas charging and accumulation is controlled by early buoyancy and later molecular expansive force respectively. It is widely distributed in anticlinal zones, deep sag areas and slopes, and is controlled by source kitchens (S), reservoirs (D), cap rocks (C), stable tectonic settings (W), low fluid potential areas $(\mathrm{P})$, and universal reservoir densification (L). Tight gas resources with great resource potential are widely distributed worldwide, and tight gas in China that presents advantageous reservoir-forming conditions is primarily found in the Ordos, Sichuan, Tarim, Junggar, and TurpanHami basins of central-western China. Tight gas has served as the primary impetus for global unconventional natural gas exploration and production under existing technical conditions.

Keywords Tight sandstone gas - Reservoir features . Accumulation mechanism - Type classification . Development mode 


\section{Introduction}

The field of tight sandstone gas exploration has witnessed global breakthroughs since the resource was first discovered in the San Juan Basin of the USA in 1927. Tight sandstone gas, belonging to unconventional gas reservoirs, is mainly found in North America, the Asia-Pacific region, Europe, and the Middle East, with total proven reserves of around $210 \times 10^{12} \mathrm{~m}^{3}$ (IEA 2009). Recently, it has served as the main source of global natural gas reserve and production growth (Zou et al. 2011a; Dai et al. 2012; Pang et al. 2013).

Given the considerable resource potential of tight sandstone gas, a series of studies have focused on development conditions, accumulation mechanisms, and type classifications. Accumulation mechanisms involving relative permeability sealing, diagenesis sealing, force balance sealing, and lateral fault sealing have been proposed (Masters 1979; Gies 1984; Jiang et al. 2000, 2006; Pang et al. 2003; Jin et al. 2003). However, accumulation controlling factors, modes, and mechanisms of tight sandstone gas are poorly understood. Based on a review of previous studies of tight sandstone gas and through a detailed case study of typical tight sandstone gas reservoirs found in China, this paper discusses accumulation mechanisms, type classifications, accumulation controlling factors, development modes, and resource potential of tight sandstone gas. Such efforts will play a significant role in enriching natural gas geological theories and in advancing the exploration and development of tight sandstone gas.

\section{Concepts and exploration of tight sandstone gas}

\subsection{Tight sandstone gas concepts}

Tight sandstone gas is natural gas contained in tight sandstone reservoirs with porosity of $<10 \%$ and in situ permeability of $<0.1 \times 10^{-3} \mu \mathrm{m}^{2}$, which belongs to unconventional gas reservoirs. Tight sandstone gas is mainly found in densified reservoirs with micro-nano pores and throats, having generally limited or no natural productivity that is typically less than the lower bound of industrial gas flows. The industrial gas production can be obtained only under specific economic and technical conditions (hydraulic fracturing reform measures or horizontal and multi-lateral wells) (Zou et al. 2011a). The tight sandstone gas has become an important field of natural gas exploration and development in recent years owing to its great resource potential (Dai et al. 2012; Zou et al. 2013).

Concepts of tight sandstone gas have varied under different technical and economic conditions at different times and in different countries. Masters (1979) first presented a definition of deep basin gas, and several other researchers have attempted to refine its description in the following terms: "tight sandstone gas reservoir," "flip-type syncline gas reservoir," "basin-centered gas reservoir," "continuous gas reservoir," "source-contacting gas," etc. (Masters 1979; Walls 1982; Dai 1983; Rose et al. 1984; Law and Dickinson 1985; Schmoker 1995; Jiang et al. 2000, 2006; Jin et al. 2003; Zhang 2006; Zou et al. 2011a) (Table 1). However, these discrimination criteria are derived from geological features without concern for essential issues pertaining to tight sandstone gas genesis.

A unified classification of tight sandstone gas reservoirs has not been created. Definitions of tight sandstone gas reservoirs are continuously improved (Table 2). In 1978, the US Federal Energy Regulatory Commission (FERC) first created the now prevailing criteria for tight sandstone gas reservoirs with the in situ permeability of less than $0.1 \times 10^{-3} \mu \mathrm{m}^{2}$. Spencer also offered a criterion of reservoir permeability of less than $0.1 \times 10^{-3} \mu \mathrm{m}^{2}$ (Spencer 1985). A consensus in terms of geological evaluation criteria for tight sandstone gas has been reached gradually with intense debate. In 2010, the China National Petroleum Corporation (CNPC) proposed a trade standard for China as reservoir porosity $<10 \%$, in situ permeability

Table 1 Definitions of tight sandstone gas

\begin{tabular}{|c|c|c|}
\hline & Main evidence & Scholars \\
\hline Deep tight reservoirs & Geological conditions and features & $\begin{array}{l}\text { Masters (1979), Gies (1984), Jiang (2000, 2006), } \\
\text { Jin (2003), Ma (2008), Pang et al. (2003) }\end{array}$ \\
\hline Flip-type syncline reservoirs & $\begin{array}{l}\text { Hydrocarbon-water distribution } \\
\text { relationship }\end{array}$ & Dai (1983), Chen (1998), Wu et al. (2007) \\
\hline Tight sandstone gas reservoirs & Reservoir physical properties & $\begin{array}{l}\text { Spencer (1989), Surdam (1997), Yang and Pang (2012), } \\
\text { Yang et al. (2013) }\end{array}$ \\
\hline Continuous gas reservoirs & Reservoir continuity & Schmoker $(1995,2002,2005)$ \\
\hline Basin-centered gas reservoirs & Distribution zones in basins & Law (2002), Rose et al. (1984), Chen et al. (2003) \\
\hline $\begin{array}{l}\text { Source-contacting gas } \\
\text { reservoirs }\end{array}$ & Gas source characteristics & Zhang et al. (2000) \\
\hline
\end{tabular}


Table 2 Tight sandstone gas classification criteria

\begin{tabular}{ll}
\hline $\begin{array}{l}\text { Scholars or } \\
\text { organizations }\end{array}$ & Classification criteria \\
\hline FERC (1978) & Original reservoir permeability $\leq 0.1 \times 10^{-3} \mu \mathrm{m}^{2}$ \\
Wyman (1985) & Porosity $<10 \%$, permeability $\leq 0.1 \times 10^{-3} \mu \mathrm{m}^{2}$ \\
Spencer (1985, 1989) & In situ permeability $\leq 0.1 \times 10^{-3} \mu \mathrm{m}^{2}$ \\
Surdam (1997) & Permeability $\leq 1 \times 10^{-3} \mu \mathrm{m}^{2}$ \\
Guan and Niu (1995) & Porosity $\leq 12 \%$, permeability $\leq 1 \times 10^{-3} \mu \mathrm{m}^{2}$, gas saturation $\leq 60 \%$, water saturation $>40 \%$ \\
Dai et al. (1996) & Porosity $<10 \%$, permeability $\leq 0.5 \times 10^{-3} \mu \mathrm{m}^{2}$ \\
Yuan et al. (1996) & Porosity $<12 \%$, surface permeability $\leq 1 \times 10^{-3} \mu \mathrm{m}^{2}$, strata permeability $<1 \times 10^{-3} \mu \mathrm{m}^{2}$ \\
Wang et al. (2004) & Porosity $2 \%-8 \%$, permeability: $(0.1-0.001) \times 10^{-3} \mu \mathrm{m}^{2}$ \\
Yang et al. (2005) & Porosity $7 \%-12 \%$, air permeability $\leq 1.0 \times 10^{-3} \mu \mathrm{m}^{2}$, pore throat radius $<0.5 \mu \mathrm{m}$ \\
Holditch (2006) & Permeability $\leq 0.1 \times 10^{-3} \mu \mathrm{m}^{2}$ \\
Nehring (2008) & Permeability $<1 \times 10^{-3} \mu \mathrm{m}^{2}$ \\
USGS & Pore throat diameter $0.03-2 \mu \mathrm{m}$ \\
IEA (2009) & Permeability $\leq 0.1 \times 10^{-3} \mu \mathrm{m}^{2}$ \\
CNPC & Overburden matrix permeability $<0.1 \times 10^{-3} \mu \mathrm{m}^{2}$, pore throat radius $<1 \mu \mathrm{m}$, porosity $<10 \%$, gas saturation $<60 \%$ \\
NEA (2011) & Overburden matrix permeability $<0.1 \times 10^{-3} \mu \mathrm{m}^{2}$ \\
Zou et al. (2011a) & Porosity $<10 \%$, permeability $\leq 1 \times 10^{-3} \mu \mathrm{m}^{2}$ \\
Pang et al. (2013) & Porosity $\leq 12 \%$, effective permeability $\leq 0.1 \times 10^{-3} \mu \mathrm{m}^{2}$ (absolute permeability $\left.\leq 1 \times 10^{-3} \mu \mathrm{m}^{2}\right)$ \\
\hline
\end{tabular}

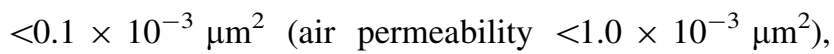
and gas saturation $<60 \%$ (SY/T6832-2011), and these criteria play a key role in guiding geological evaluation and exploration of tight sandstone gas in China.

\subsection{Overview of tight sandstone gas exploration}

\subsubsection{Overview of world tight sandstone gas exploration activities}

The world's tight gas resources are mainly found in North America, the Asia-Pacific region, Europe, and the Middle East (Law 2002; Schmoker 2005; Zou et al. 2011a; Dai et al. 2012; Zhao et al. 2012; Yang et al. 2012). Tight gas reservoirs in North America, distributed across roughly 20 basins in the Rocky Mountain Basin Group and the Gulf Coast, are regarded as some of the most typical reservoirs (Law 2002; Lei et al. 2010). The San Juan Basin includes a large gas-bearing area of deep tight gas of approximately $9325 \mathrm{~km}^{2}$, with porosity ranging from $5.8 \%$ to $7.6 \%$, permeability varying from $0.01 \times 10^{-3}$ to $0.15 \times 10^{-3}$ $\mu \mathrm{m}^{2}$, and with geological reserves of some $0.90 \times 10^{12} \mathrm{~m}^{3}$ (Fig. 1a). The Red Desert Basin covers an area of $2400 \mathrm{~km}^{2}$, with porosity ranging from $3.0 \%$ to $7.0 \%$, with permeability falling below $1.0 \times 10^{-3} \mu \mathrm{m}^{2}$, and with geological reserves of $1.4 \times 10^{12} \mathrm{~m}^{3}$ (Fig. 1b). The Greater Green River Basin covers an area of $51,022 \mathrm{~km}^{2}$, with porosity ranging from $8.0 \%$ to $12.0 \%$, with permeability

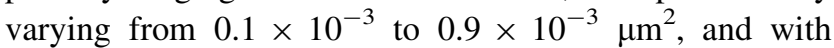

geological reserves of around $0.26 \times 10^{12} \mathrm{~m}^{3}$ (Fig. 1c). The Elmworth deep tight gas in the western depression of the Alberta Basin is the largest natural gas reservoir in North America. It covers a gas-bearing area of $13,000 \mathrm{~km}^{2}$ with a Cretaceous reservoir thickness of $3000 \mathrm{~m}$, an average porosity of $8.0 \%$, permeability less than $1.0 \times 10^{-3} \mu^{2}$, and with geological reserves of $4.8 \times 10^{12} \mathrm{~m}^{3}$ (Fig. 1d).

Tight sandstone gas has become a major source of global natural gas reserves and production growth (Schmoker 2005; IEA 2009; Zou et al. 2010). Tight sandstone gas has been commercially exploited on a large scale in more than 10 countries including the United States, Canada, and China, with the United States being the first to successfully develop and exploit the resource, and now it is the world leader in this field. Tight sandstone gas exploration and development began in the late 1970s, and by 2010, American research teams had identified roughly 900 tight gas fields across 23 basins with more than $10 \times 10^{4}$ production wells and with gas production of $1754 \times$ $10^{8} \mathrm{~m}^{3}$, accounting for roughly $26 \%$ of total natural gas production in the United States. By 2013, tight sandstone gas production accounted for a third of total US natural gas production (IEA 2013).

\subsubsection{Overview of tight sandstone gas exploration in China}

The discovery of the Zhongba gas field in the western Sichuan Basin in 1971 is considered to have initiated tight gas exploration and research in China, with tight sandstone 

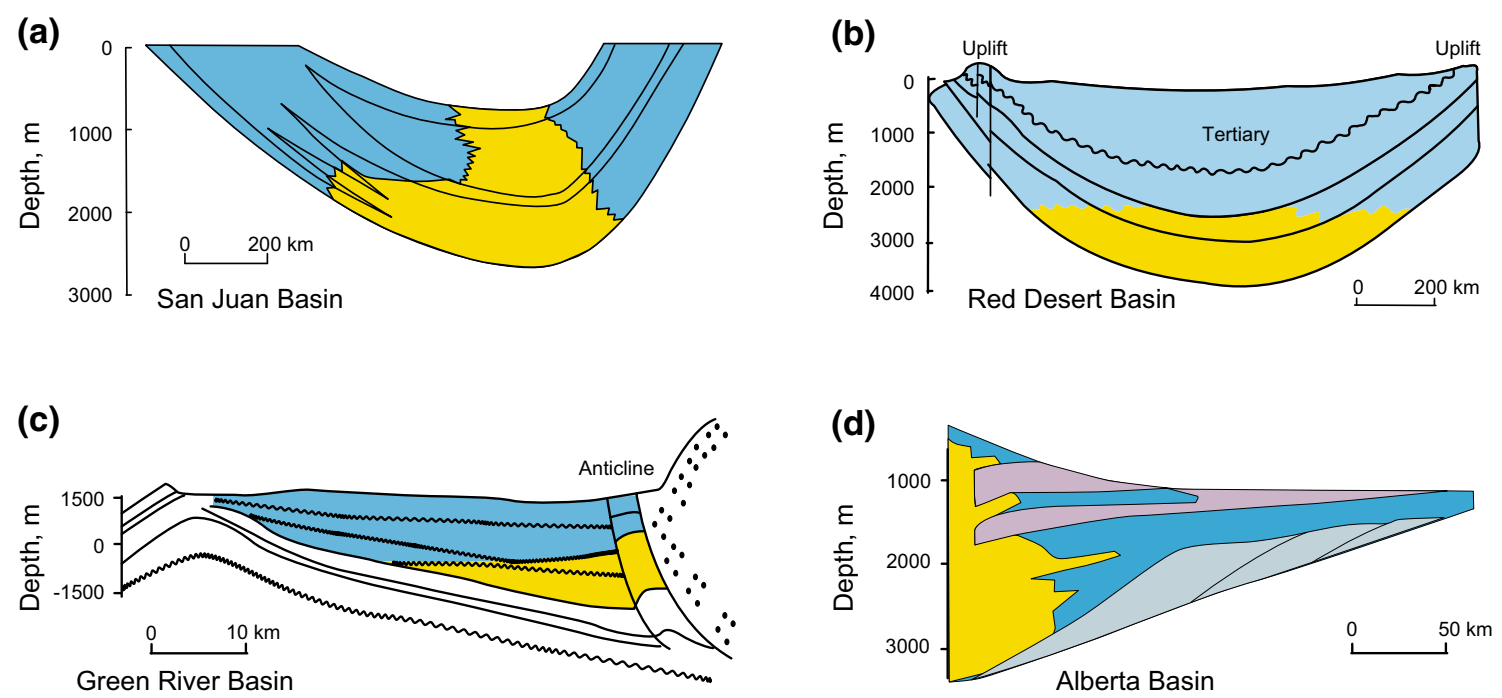

Fig. 1 Typical tight sandstone gas reservoirs in the USA (Modified from Masters 1979; Law 2002). a Cretaceous gas reservoirs in the San Juan Basin; b Cretaceous gas reservoirs in the Red Desert Basin; c Cretaceous, Paleogene, and Neogene gas reservoirs in the Greater Green River Basin; d Cretaceous gas reservoirs in the Alberta Basin

gas reserves later being found in the Ordos Basin. However, tight sandstone gas exploration efforts progressed slowly due to a lack of effective evaluation criteria and engineering technologies. In recent years, tight sandstone gas exploration and production have obtained considerable breakthroughs through the application of fracturing technologies. The geological reserves of tight gas reached $3.3 \times 10^{12} \mathrm{~m}^{3}$ in 2011 , accounting for roughly $39 \%$ of total proven reserves of natural gas. The production of tight gas in 2012 and 2013 yielded $300 \times 10^{8}$ and $340 \times 10^{8}$ $\mathrm{m}^{3}$, respectively, accounting for roughly $28 \%$ of total natural gas production. Tight gas has in turn emerged as the most feasible unconventional gas resource (Dai et al. 2012; Pang et al. 2014).

Ideal geological conditions for tight sandstone gas development (wide distribution and various types) are found in China. Five major confirmed gas-bearing areas include the Ordos, western Sichuan, Tarim, southern Junggar, and Songliao faulted basins. The Ordos and Sichuan Basins have been identified as the tight sandstone gas-bearing areas with the greatest resource potential (Dai et al. 2012; Zou et al. 2012; Zhao et al. 2012).

\section{Tight sandstone gas reservoir features}

\subsection{Reservoir densification and wide distribution}

Reservoir densification is the most essential feature of tight sandstone gas. The tight sandstone gas reservoir of the Green River Basin in the United States has porosity ranging from $4.7 \%$ to $11.7 \%$ and permeability ranging from $0.001 \times 10^{-3}$ to $0.05 \times 10^{-3} \mu \mathrm{m}^{2}$. The tight sandstone gas reservoir of the Alberta Basin in Canada has porosity ranging from $3 \%$ to $13 \%$ and permeability ranging from $0.005 \times 10^{-3}$ to $0.015 \times 10^{-3} \mu \mathrm{m}^{2}$. The tight sandstone gas reservoir of the Ordos Basin has porosity ranging from $1 \%$ to $12 \%$ and permeability ranging from $0.01 \times 10^{-3}$ to $1 \times 10^{-3} \mu^{2}$. The tight sandstone gas reservoir in the Xujiahe Formation of the central Sichuan Basin has porosity ranging from $4 \%$ to $10 \%$, and samples with in situ permeability $<0.1 \times 10^{-3} \mu \mathrm{m}^{2}$ account for roughly $80 \%-92 \%$ (Zou et al. 2011a) (Table 3). Compared with conventional reservoirs, heterogeneous tight reservoirs are characterized by nano pores, with milli-micro pores developing locally. Mercury injection data for typical samples show that $77.2 \%$ of samples have nano pores with a radius of $<1 \mu \mathrm{m}$, and for tight sandstone gas reservoirs in the Sulige area of the Ordos Basin, pores and throats with a radius of $<1 \mu \mathrm{m}$ account for $83.6 \%$. Most reservoir spaces consist of intergranular pores, intragranular pores, intercrystal pores, and intergranular cracks, which provide the majority of space for natural gas (Zou et al. 2011b).

In China, the presence of tight sandstone gas is often related to the development of coal strata, as acidic sedimentary, diagenetic and extruded anticline structure environments serve as the main reasons of sandstone densification, where diagenesis processes have the greatest influence and mainly involve compaction, cementation, replacement, dissolution, and clay mineral transformation. Compaction (mechanical and chemical) and cementation serve as the main driving forces behind reservoir densification ( $\mathrm{Li}$ et al. 2012). 
Table 3 Physical properties of typical tight sandstone gas reservoirs in China

\begin{tabular}{|c|c|c|c|c|c|c|c|}
\hline & $\begin{array}{l}\text { Ordos } \\
\text { Basin }\end{array}$ & $\begin{array}{l}\text { Sichuan } \\
\text { Basin }\end{array}$ & $\begin{array}{l}\text { Southern Songliao } \\
\text { Basin }\end{array}$ & $\begin{array}{l}\text { Turpan-Hami } \\
\text { Basin }\end{array}$ & $\begin{array}{l}\text { Junggar } \\
\text { Basin }\end{array}$ & Tarim Basin & \\
\hline Strata & $\mathrm{C}-\mathrm{P}$ & $\mathrm{T}_{3} \mathrm{x}$ & $\mathrm{K}$ & $\mathrm{J}_{1}$ & $\mathrm{~J}_{1} \mathrm{~b}$ & $S$ & $\mathrm{~J}$ \\
\hline Depth, m & $2000-5200$ & $2000-5200$ & $2200-3500$ & $3000-3650$ & $4200-4800$ & $4800-6500$ & $3800-4900$ \\
\hline \multicolumn{8}{|l|}{ Porosity } \\
\hline Mean, \% & 6.695 & 4.200 & 3.200 & 5.012 & 9.100 & 6.513 & 2.780 \\
\hline Average, $\%$ & 6.930 & 5.65 & 3.350 & 5.160 & 9.040 & 6.980 & 6.490 \\
\hline Sample number & 6015 & 39,999 & 61 & 25 & 51 & 1019 & 4720 \\
\hline \multicolumn{8}{|l|}{ Permeability } \\
\hline Mean, $\times 10^{-3} \mu \mathrm{m}^{2}$ & 0.229 & 0.057 & 0.034 & 0.047 & 0.455 & 0.205 & 0.393 \\
\hline Average, $\times 10^{-3} \mu \mathrm{m}^{2}$ & 0.604 & 0.351 & 0.224 & 0.106 & 1.250 & 3.572 & 1.126 \\
\hline Sample number & 5849 & 32,351 & 52 & 25 & 43 & 988 & 4531 \\
\hline
\end{tabular}

Tight sandstone gas reservoirs are also distributed across large areas and are positioned vertically adjacent to source rocks, which is a key to tight sandstone gas reservoir accumulation. For example, the upper Paleozoic strata of the Ordos Basin are composed of a series of sediments of transitional facies and fluvial-delta facies, resulting in poor sandstone physical properties but horizontally wide distribution that covers nearly the entire basin and vertically multi-layered development (found in the Benxi, Taiyuan, Shanxi, and Xiashihezi Formations). In brief, tight sandstone gas reservoirs present features of vertically multilayered and horizontally large area superimposed distribution (Li et al. 2012).

\subsection{Source rocks mainly from coal and adjacent to reservoirs}

For tight sandstone gas reservoirs, coal source rocks are characterized by wide distribution, high TOC, and high hydrocarbon-generating intensity. The results of hydrocarbon generation simulation experiments show that coal can continuously generate and expel hydrocarbon while charging reservoirs with no gas generation peak level, even during highly thermal evolution stages. The Sulige gas field of the Ordos Basin, gas fields in the western Sichuan Depression of the Sichuan Basin and tight sandstone gas reservoirs in the Kuqa Depression of the Tarim Basin are primarily associated with coal strata, which can indeed generate continuous and abundant natural gas. This period of large-scale gas generation has been relatively late and considerably long (it still continues), thus facilitating the formation of tight sandstone gas reservoirs (Zou et al. 2011a; Li et al. 2012).

Source rocks of tight sandstone gas reservoirs are distributed widely and are located either within reservoirs or adjacent to them, and this can result in a considerable increase in expulsion efficiency from source rocks to reservoirs for large contacting areas and short distances, presenting sheet-like generating and diffuse hydrocarbon charging properties. For instance, for the Dibei tight gas reservoir in the eastern Kuqa Depression of the Tarim Basin, the source rocks (Triassic coal strata of the Taliqike Formation and lacustrine mudstone of the Huangshanjie Formation) make a close contact with the lower Jurassic tight sandstone reservoirs of the Ahe and Yangxia Formations. This facilitates the large-scale accumulation of tight sandstone gas (Zhou 2002; Liang et al. 2004; Wang 2014).

Tight sandstone gas reservoirs are also found adjacent to widely distributed source rocks and are characterized by short-distance seepage diffusion and non-Darcy seepage migration processes, which can improve accumulation efficiency (Zou et al. 2012). For example, the upper Paleozoic sandstone strata of the Ordos Basin present horizontally wide distribution and poor physical properties, indicating that gas largely migrates only short distances laterally within the tight sandstone. A lack of faults also results in an absence of long-distance vertical migration. Source-proximal hydrocarbon accumulation thus dominates without long-distance vertical and lateral migration.

\subsection{Complex gas and water distribution and pressure anomalies}

Intricate relationships between gas and water in tight sandstone gas reservoirs are attributed to the fact that the relationship between gas and water is not controlled by structural contours, and thus no unified gas-water interface or even gas-water inversion processes are present (where gas accumulates below water, rather than above it as usual). The Upper Paleozoic tight gas reservoirs, for instance, show complicated gas-water relationships with 
the presence of water during tight gas operation, no clear regional gas-water inversion processes or apparent edge or bottom water features. Furthermore, gas-water relationship complications are related to highly heterogeneous and well-developed micro-nano pores in tight sandstone reservoirs and show an affinity with gas charging and migration processes. Buoyancy no longer acts as the driving force for natural gas migration and accumulation. Gas rarely migrates long distances within tight sandstone reservoirs and accumulates over short migration distances, typically resulting in poor gas-water differentiation, tangled distribution, and a large number of small water bodies.

Tight sandstone gas reservoirs have no uniform pressure systems and often present pressure anomalies (Wang 2002). For instance, most tight sandstone gas reservoirs of the Alberta, San Juan, and Denver Basins present abnormally low pressure, while those of the Green River, Piceance, and Utah Basins largely show abnormally high pressure (Fig. 2). In China, tight sandstone gas reservoirs in the western Sichuan Depression of the Sichuan Basin and Kuqa Depression of the Tarim Basin also show abnormally high pressure, and those in the Xiaocaohu area of the Turpan-Hami Basin show abnormally low pressure. In comparison with those cases described above, the Upper Paleozoic tight gas reservoirs of the Ordos Basin show complex pressure systems with pressure coefficients varying greatly across all pressure range (i.e., negative, atmospheric, and overpressure). Furthermore, even within the same gas field or the same horizon, pressure varies considerably, denoting the presence of multiple pressure systems and of poor connectivity between them (Zhao et al. 2012).

\subsection{Complex distribution and the high resource potential of tight gas reservoirs}

Sandstone is found in large quantities in tight gas reservoirs and is typically superimposed in large continuous sheets in the plane with no definite traps, and tight sandstone gas reservoirs are developed in deep concave central areas or in downdip areas of structural slope belts, and structural highlands. Tight sandstone gas reservoirs in the United States are commonly found in downdip areas of foreland basins, in central areas of frontal uplifts, and in deep structural basin synclines. Tight sandstone gas reservoirs in China are mainly developed in downdip areas of basin slopes and in deep structural basin synclines and anticlines. Small reservoirs are also found in central basin areas or in deep depressions, and this distribution may possibly be related to the current low level of exploration.

Furthermore, even though tight sandstone gas reservoirs present large gas-bearing areas, their enrichment is controlled by sweet spots and fractures, and they show signs of partial accumulation (Zhao et al. 2004; Yang et al. 2007). Sweet spots are considered to be central to tight reservoirs. The USGS in 1999 first defined sweet spots as resource blocks that are capable of offering continuous stable production for 30 years. Law (2002) proposed that sweet spots are composed of tight sandstone zones with relatively high porosity and permeability. Sweet spots are now commonly used to study unconventional resources and are defined as local zones of higher porosity and permeability that are capable of offering relatively high daily gas production and continuous economic production within areas with poor physical properties. Sweet spots can be divided into two types: "Pore" sweet spots and "Fracture" sweet spots. "Pore" sweet spots are mainly controlled by sedimentation and diagenesis processes, and "Fracture" sweet spots are controlled by fracture distribution, with structural fractures serving as the most critical factor (Yang et al. 2013).

Fractures control the tight gas reservoir distribution, as they can greatly improve physical properties of reservoirs, in particular permeability. In addition, fractures serve as storage space for reservoir fluid and as the main pathway for reservoir fluid migration, which in turn determine the distribution of seepage systems in tight gas reservoirs, resulting in the stable and significant production of tight gas reservoirs. Meanwhile, fractures also determine natural gas migration and accumulation, as buoyancy prevails within wide fractures, while molecular expansion forces dominate within matrix pores. In serving as the main forcing mechanism of natural gas accumulation and production, fracture systems can further improve the potential value of tight reservoirs.

\section{Tight sandstone gas reservoir accumulation mechanisms and classifications}

\subsection{Model testing and mechanism interpretation of tight sandstone gas}

Whether buoyancy serves as the main driving force for the accumulation of tight sandstone gas reservoirs is still debated. Buoyancy conditions have been detected in reservoir settings in numerous physical simulation works (Gies 1984; Zeng 2000; Pang et al. 2003; Xiao et al. 2008; Pang et al. 2014), which include capillary simulation and quartz sand simulation experiments.

\subsubsection{Capillary simulation experiments}

Buoyancy accumulation processes have been examined through capillary physical modeling in previous studies (Fig. 3). 


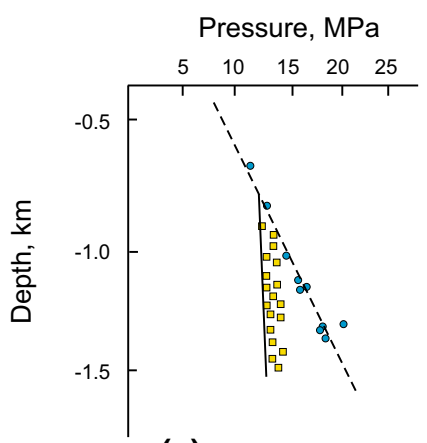

(a) Northern Alberta Basin (Falher A)

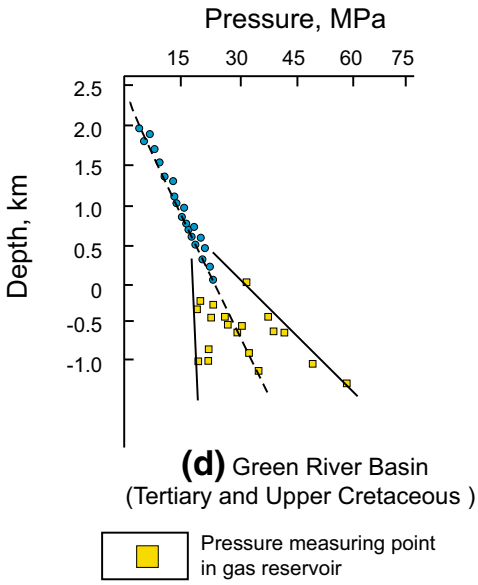

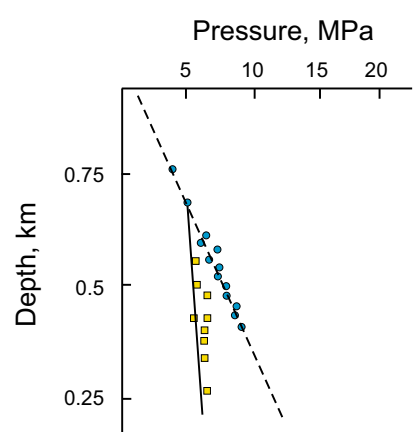

(b) Southern Alberta Basin (Milk River)

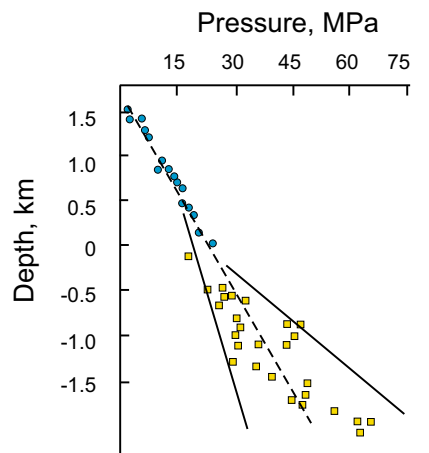

(e) Red Desert Basin

Pressure measuring point in water layer

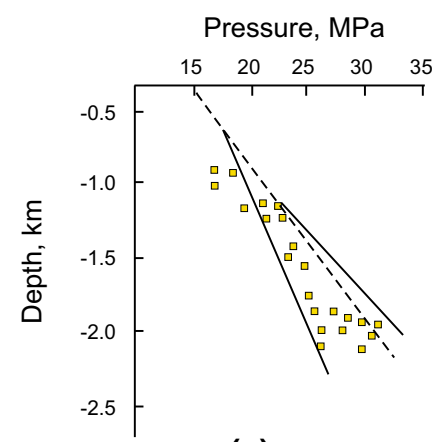

(c) Ordos Basin (Upper Paleozoic)

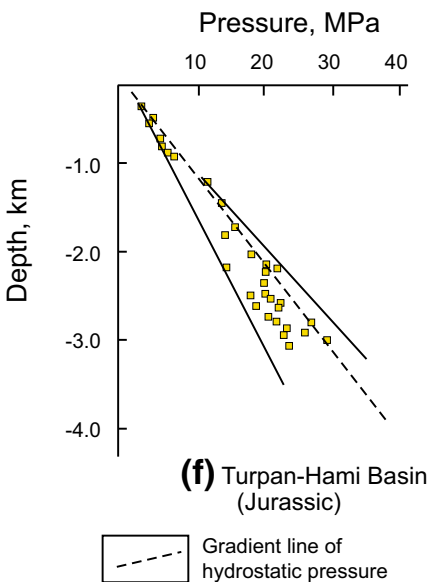

Fig. 2 Pressure distribution of typical tight sandstone gas reservoirs in China and abroad (Wang 2002)

A single homogeneous capillary physical model for hydrosealed threshold measurements has shown that oil and gas injected into the bottom of a glass tube and accumulating in the lower segment without upward migration processes is not affected by buoyancy when the diameter of a glass tube filled with water is less than $4.5 \mathrm{~mm}$, thus proving the lower limit of buoyancy accumulation (Pang et al. 2003).

A capillary physical model was also used in an experiment involving a cone-shaped glass tube, and the critical diameter of pores and throats for hydrosealing was measured to be between 0.10 and $0.36 \mathrm{~cm}$ (Pang et al. 2003).

A capillary physical model with a smaller glass tube characterized by changeable cone shapes showed that pore and throat radii corresponding to the lower limit of buoyancy accumulation decrease with an increase in hydrostatic pressure and oil injection pressure (Pang et al. 2013).

In addition, reservoir crack widths were modeled in a physical model based on gap distances between glass slides, which were conducted by using $0.02-\mathrm{mm}$-thick tinfoil. Gas drainage induced by gas injection into the experimental installation filled with red ink was observed, and gas-water inversion only occurred when crack widths were less than $0.02 \mathrm{~mm}$.

\subsubsection{Quartz sand simulation experiments}

Recent studies have also studied the importance of buoyancy as a critical geological factor with quartz sand simulation experiments (Fig. 4).

Pressure models with glass pillars developed by Gies (1984) show that gas-water inversion processes can be observed in fine sand without buoyancy control but not in coarse sand.

Physical models of oil-gas migration processes with sandfilled glass tubes show that gas and oil, respectively, injected upwards into a glass tube always accumulates in sand of the lower segment without engaging in upward migration affected by buoyancy when the sand grain diameter is less than 0.1 or $0.2 \mathrm{~mm}$ (glass tube filled with water). These diameters were defined as the lower boundaries of buoyancy accumulation for gas and oil, respectively (Pang et al. 2003).

During physical modeling of hydrosealed thresholds using sand-filled glass pillars, gas-water inversion processes were observed in sand grains with diameters ranging from 0.05 to $0.1 \mathrm{~mm}$ (Pang et al. 2003). 
(a)

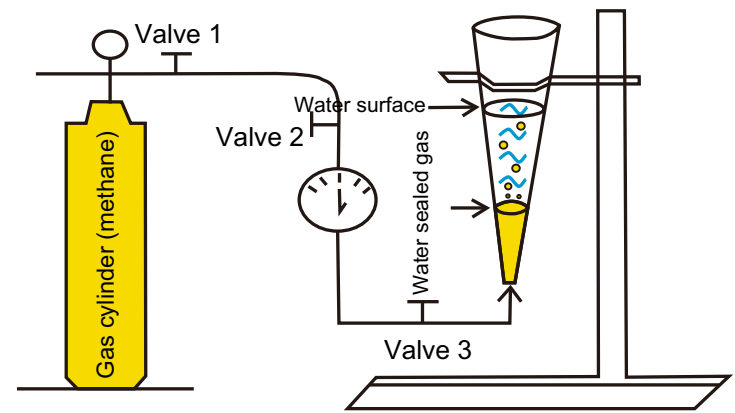

(c)

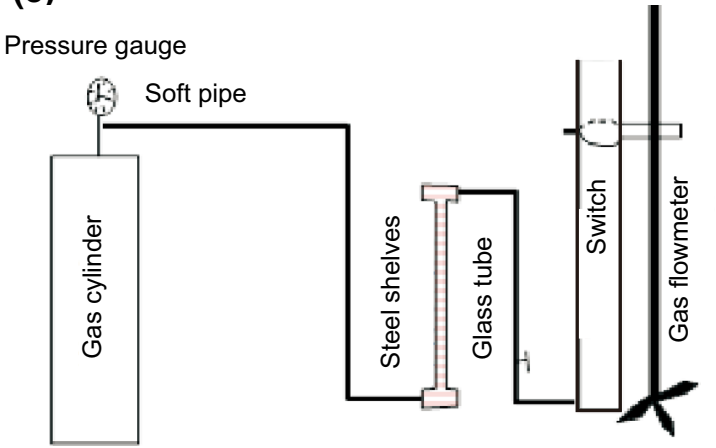

(e)

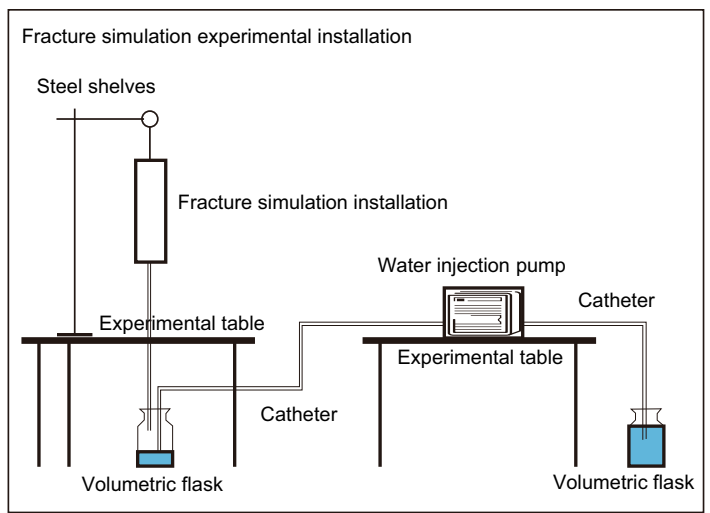

(b)

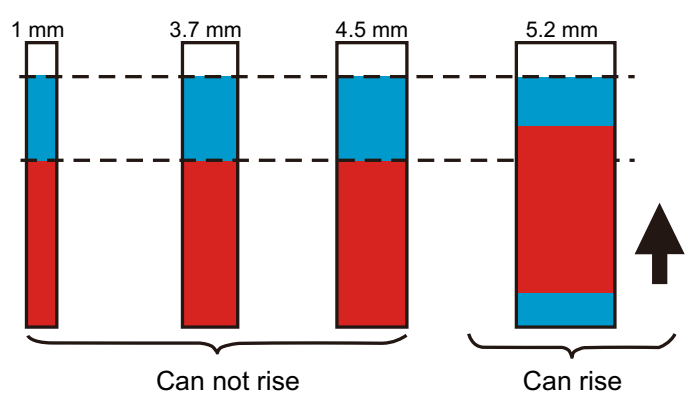

(d)

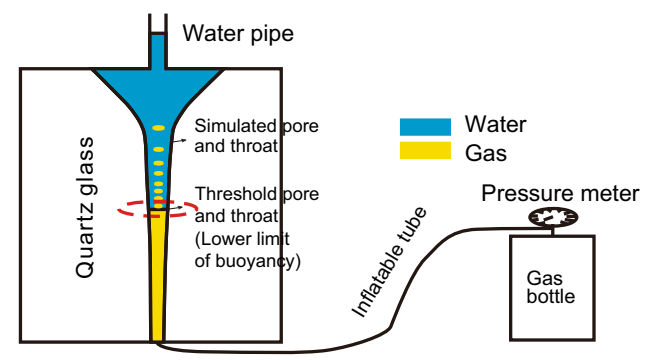

(f)

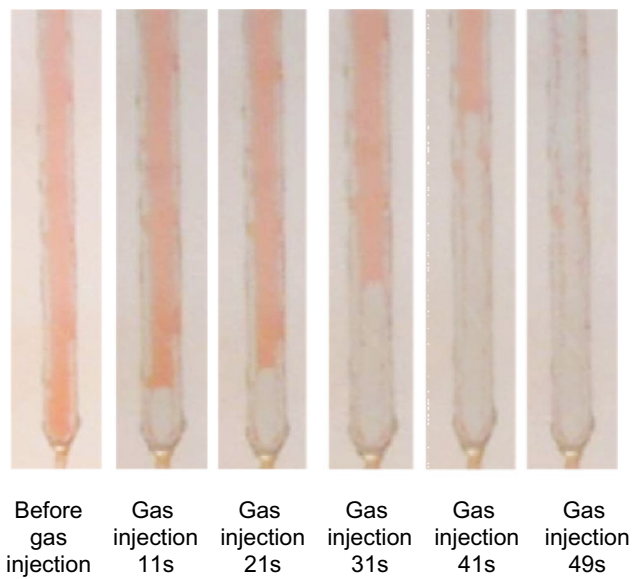

Fig. 3 Physical modeling of critical accumulation conditions. a Physical modeling of the gas-sealing threshold using a funnel-shaped capillary (Pang et al. 2003); b Zeng (2000); c Physical modeling of critical pore throat diameters using a funnel-shaped capillary (Pang et al. 2003); d Physical modeling using a cone glass tube (Pang et al. 2014); e Fracture simulation using glass slides; f Observations of fracture simulation with glass slides. The figure illustrates gas-water contact changes before and after gas injection into the glass slides

Gas injection experiments involving glass tubes have shown that pore water is displaced by natural gas injected upward that accumulates in sand grains in the bottom layer (Xiao et al. 2008).

Physical models involving larger sand-filled glass tubes placed under changing pressure conditions have shown that both pore and throat radii and sand grain diameters corresponding to the lower limit of buoyancy accumulation decrease with an increase in hydrostatic pressure and oil injection pressure in a single tube and sand-filled glass pillar, respectively (Pang et al. 2014).

Despite significant differences in temperature-pressure conditions between the physical models and real geological settings, the simulation experiments noted above are still of great importance to future research. According to the capillary and quartz sand models, capillary forces increase with a decrease in sand grain and glass tube diameters, resulting in the invalidation of buoyancy as the most 

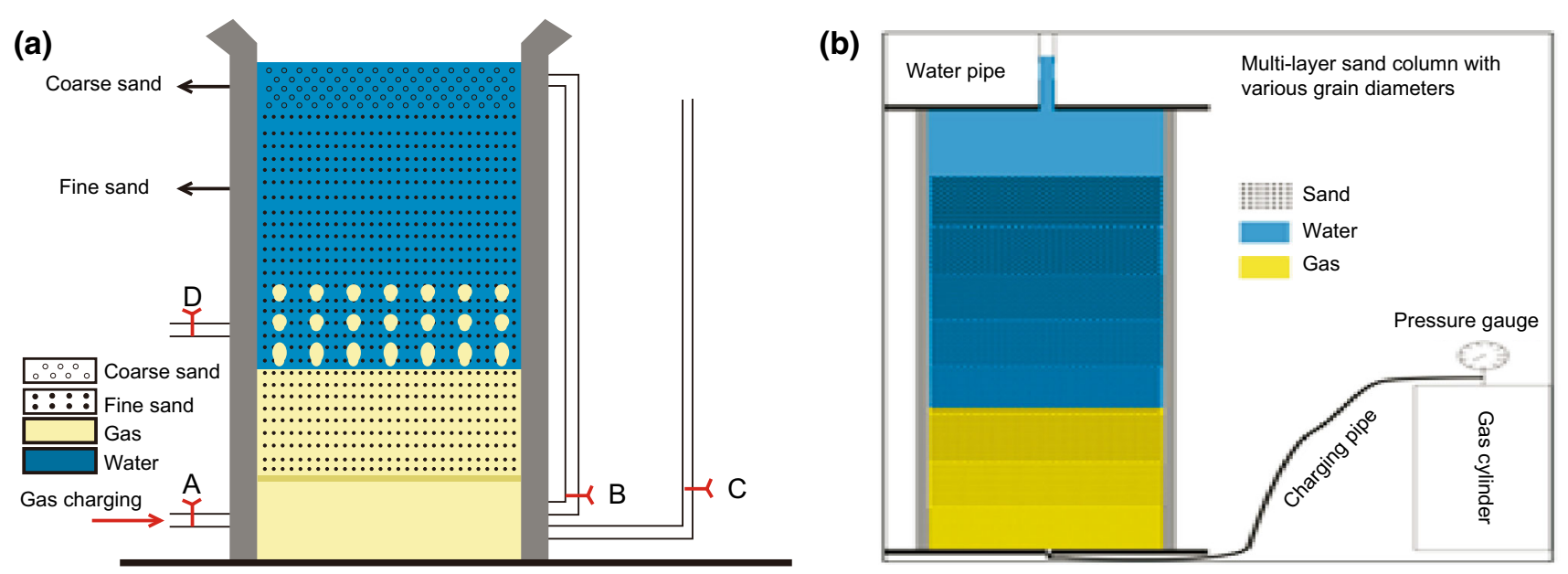

(c)
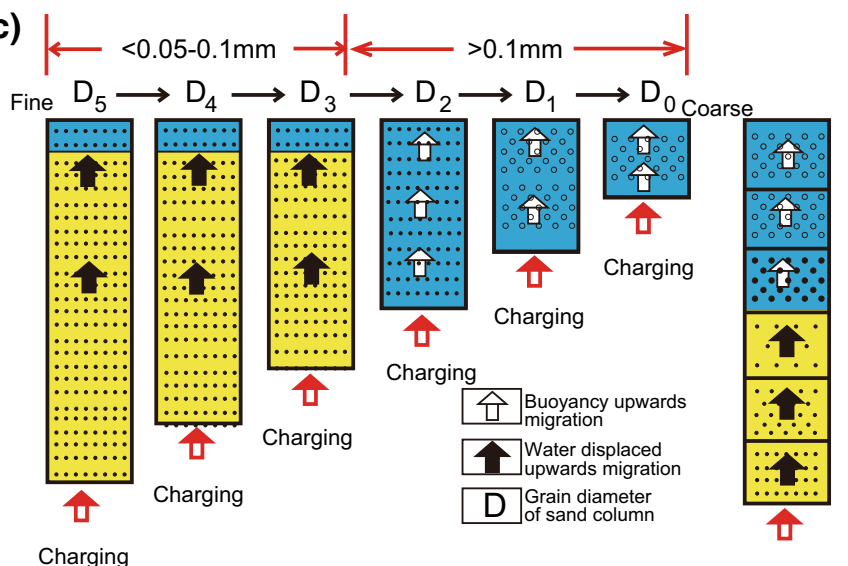

(d)

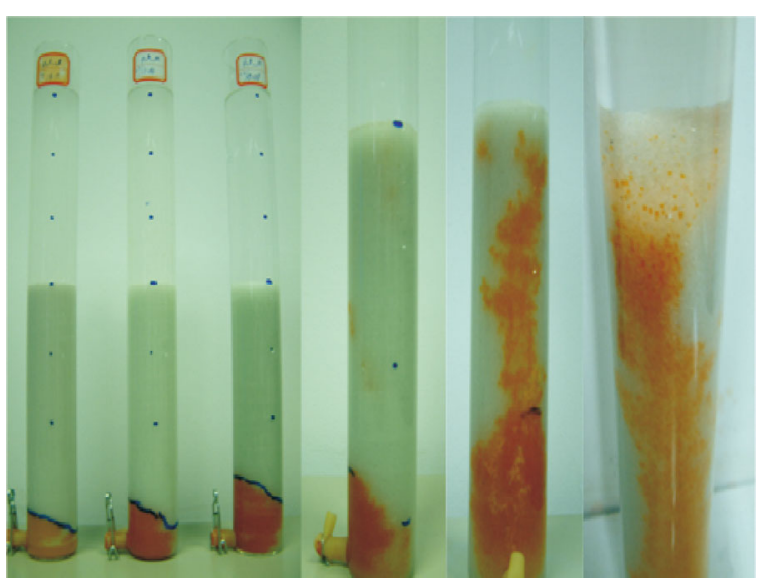

Fig. 4 Quartz sand simulation experiments. a Pressure simulation involving a glass column (Gies 1984); b Physical modeling involving a sandfilled glass tube under pressure-changing conditions (Pang et al. 2014); c Physical modeling of gas-sealing thresholds involving a thick glass tube (Pang et al. 2001); d Gas injection experiments involving glass tubes have shown that pore water is displaced by natural gas injected upward that accumulates in sand grains in the bottom layer (Xiao et al. 2008)

important controlling factor. A critical geological condition without buoyancy-driven mechanism that is characterized by gas-water inversion can thus be assumed.

\subsection{Accumulation mechanisms of tight sandstone gas reservoirs}

\subsubsection{Dynamic mechanisms of "accumulation- densification" tight gas}

"Accumulation-densification" tight gas reservoirs are formed from conventional gas reservoirs that subsequently undergo densification due to compaction and diagenesis. Their formation mechanism and distribution characteristics resemble those of conventional gas reservoirs, because when gas accumulates, reservoirs are not yet densified (i.e., the completion of gas charging and accumulation occurs in conventional gas reservoirs). Densification occurs as a result of subsequent burial compaction and structural compression. Thus, buoyancy serves as the main driving mechanism for natural gas migration and accumulation, and "accumulation-densification" tight gas reservoirs are always found in structurally high positions associated with anticlines, faults, lithological lenses, and pinch out areas (Fig. 5). Sandstone reservoir densification is induced by compaction, cementation, and structural compression with compaction (mechanical and chemical) serving as major driving forces (Shou et al. 2003; Liu et al. 2006; Zhang et al. 2011).

\subsubsection{Dynamic mechanisms of "densification- accumulation" tight gas}

"Densification-accumulation" tight gas forms after reservoir densification. A large amount of gas expelled by effective source rocks migrates directly into adjacent tight 

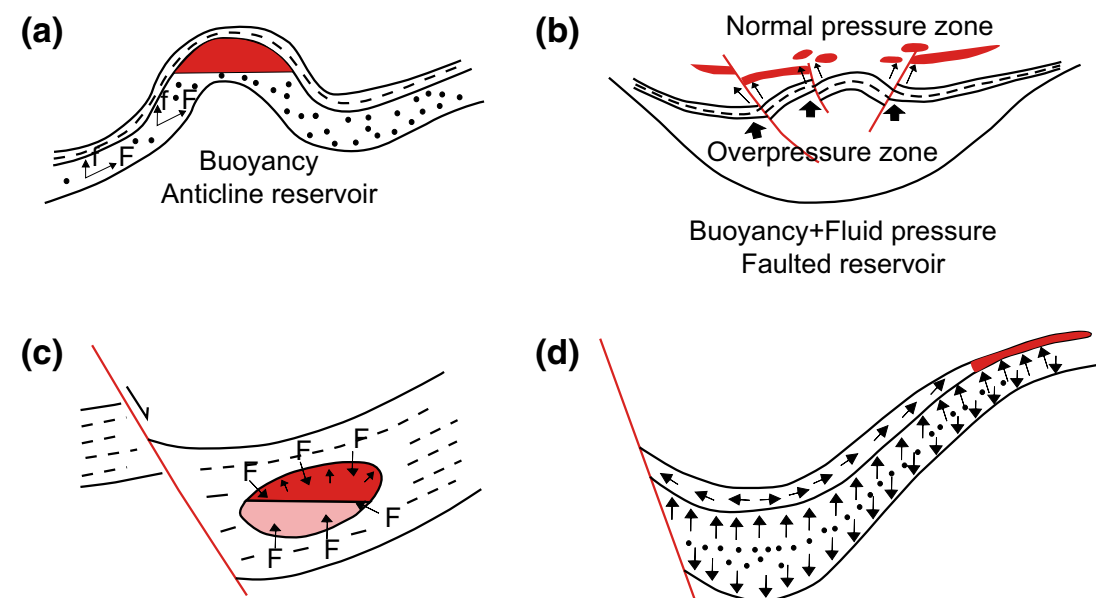

(d)

Buoyancy+Capillary force Lithologic reservoir
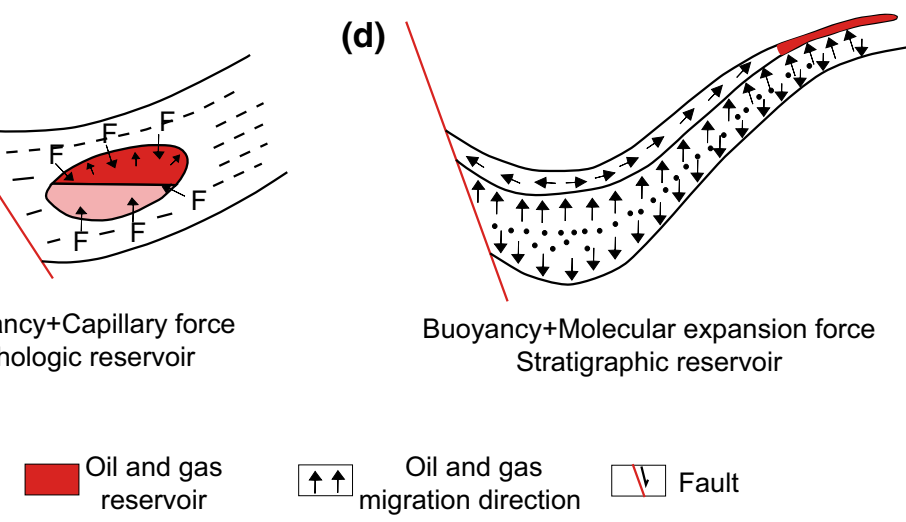

Fig. 5 Classification of tight conventional gas reservoirs (modified from Pang et al. 2014). a Anticline tight gas reservoir; b Fault-related tight gas reservoir; c Lithological lens tight gas reservoir; d Stratigraphic pinching out tight gas reservoir

reservoirs under decisive capillary forces and hydrocarbon molecular expansion force (not buoyancy). Pore water is drained to extend the gas distribution scale which is then aggregated to form continuous, large-scale deep tight gas reservoirs. "Densification-accumulation" tight gas reservoirs are always found in low structural positions (e.g., deep depression slopes or basins).

Conventional and unconventional oil and gas accumulations differ in that whether buoyancy serves as the primary driving force for hydrocarbon accumulation (Song et al. 2013). In non-buoyancy accumulation, buoyancy processes cannot overcome gas accumulation resistance and thus cannot act as the main driving force for gas accumulation. Non-buoyancy accumulation is mainly controlled by the difference between resistance and buoyancy, and strong capillary forces in reservoirs are normally induced by developed micro-nano pores.

The distribution area of deep tight gas reservoirs depends on the force balance (Fig. 6), as in critical conditions, hydrocarbon expansive forces are equal to the sum of capillary force and overburden hydrostatic pressure (Pang et al. 2003; Xie et al. 2004). Buoyancy becomes insignificant in densified reservoirs, and the potential maximum distribution area (trap area) of tight gas and minimum burial depth can be obtained using the force balance equation. In addition, the material balance of tight gas reservoirs can be described as follows: gas storage amount is equal to the gas supply amount minus the sum of gas loss from cap rocks, from the gas-water interface, and from the trap spill point. The material balance determines the distribution areas of deep basin gas traps, gas-bearing areas inside traps, and favorable exploration zone borders (Pang et al. 2003).

\subsection{Type classifications of tight sandstone gas reservoirs}

\subsubsection{Previous classifications of tight sandstone gas reservoirs and outstanding uncertainties}

Numerous scholars in China and abroad have carried out studies on accumulation mechanisms and type classifications of tight sandstone gas reservoirs. Based on reservoir characteristics, Guan and Niu (1995) divided tight sandstone gas reservoirs into three types: good (dense), moderate (overly dense), and poor (extremely dense). Law (2002) classified tight sandstone gas reservoirs in central basin areas into two types, direct and indirect, in light of organic matter types of source rocks. Jiang et al. (2006) divided tight sandstone gas reservoirs into three types, the "densification-accumulation" (DA) deep tight type and the "accumulation-densification" (AD) tight conventional type, based on hydrocarbon expulsion peak timing and reservoir densification evolution. Dong et al. (2007) classified tight sandstone gas reservoirs into reformed and original types based on relationships between tight gas accumulation and structural evolution and different accumulation principles. Zou et al. (2011a) classified tight 


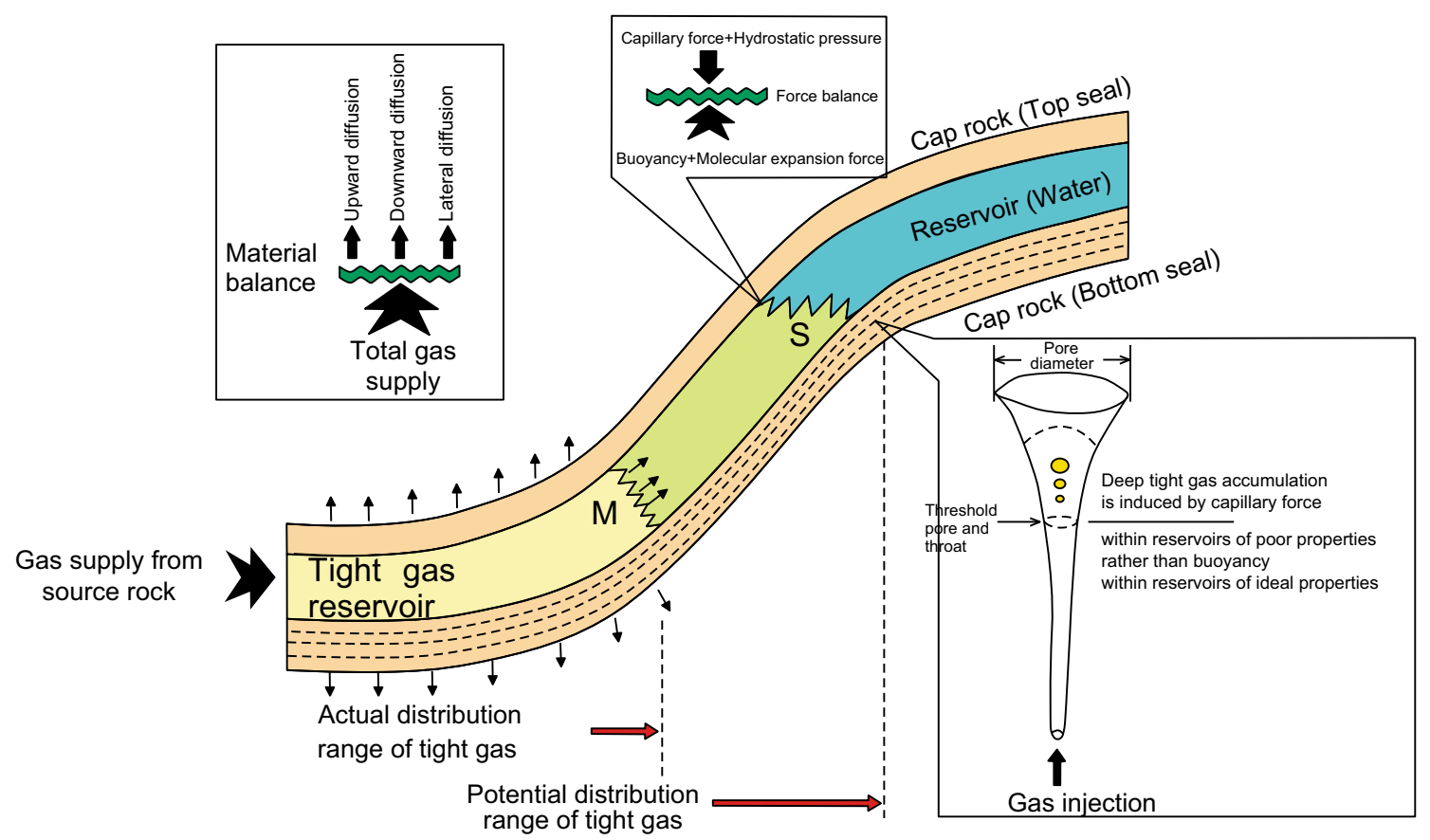

Fig. 6 Accumulation mechanisms of force and material balance for tight gas reservoirs (Pang et al. 2003)

sandstone gas reservoirs into slope lithological and deep structural types based on formation conditions, distribution characteristics, trap types, exploration practices, etc. Guo et al. (2012), based on accumulation modes, divided accumulation zones of tight sandstone gas reservoirs into continuous and transitional types. Dai et al. (2012) classified tight sandstone gas reservoirs into continuous and trap types based on reservoir characteristics, reserves, and structural locations. Li et al. (2012) classified tight sandstone gas reservoirs into slope, anticline structural, and deep sag types based on structural locations, accumulation mechanisms, and evolution principles. Zhao et al. (2012), according to trap types and distribution, proposed continuous, quasi-continuous, and non-continuous type classifications. However, all of the classifications noted above pertain to geological features of gas reservoirs, without classifying tight gas reservoirs based on accumulation dynamics.

\subsubsection{Tight gas reservoir classification based on accumulation dynamics}

On the basis of gas charging periods (GCP) and reservoir densification periods (RDP) and in consideration of dynamic features and distribution characteristics, we propose the classification of tight sandstone gas reservoirs into three types: conventional tight gas reservoirs, deep tight gas reservoirs, and composite tight gas reservoirs (Fig. 7). During the RDP, buoyancy dynamics cannot act, as critical physical properties, which vary with actual geological settings for different basins.

Conventional tight reservoirs are tight gas reservoirs in which the GCP precedes the RDP. They are formed via accumulation and subsequent densification, with buoyancy serving as the main accumulation force that also determines the distribution of tight gas reservoirs (Fig. 7a).

Deep tight gas reservoirs are defined as tight gas reservoirs in which the RDP precedes the GCP. Formation mechanisms involve densification followed by charging and accumulation under hydrocarbon generation expansive forces without buoyancy. Deep tight gas reservoirs are characterized by close contact between source rocks and reservoirs and by the continuous widespread distribution and the common presence of relatively deep depression areas or sag and slope belts (Fig. 7b).

Composite tight gas reservoirs exhibiting composite features of conventional tight gas reservoirs and deep tight gas reservoirs are characterized by accumulation and trapping in low porosity zones of structurally high areas and by distribution in structurally low areas. Gas charging occurred during both early and late stages of accumulation that involved initial accumulation followed by densification and re-accumulation. These are mainly driven by early buoyancy and a combination of hydrocarbon expansion forces and capillary forces. Composite tight gas reservoirs are distributed widely in anticline belts, deep depressions, and slope zones (Fig. 7c). 

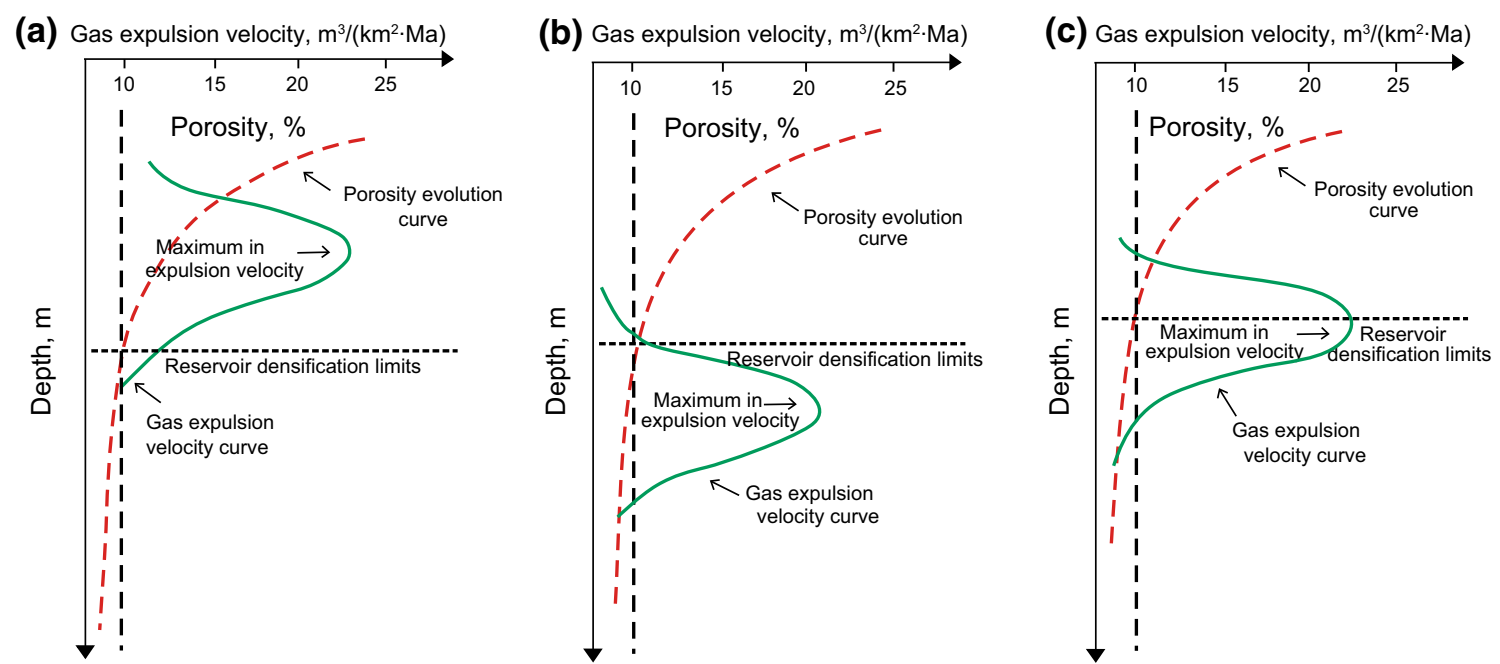

Fig. 7 Genetic type classification of tight sandstone gas reservoirs. a Conventional tight gas reservoir; b Deep tight gas reservoir; $\mathbf{c}$ Composite tight gas reservoir

\subsubsection{Characteristics of various tight sandstone gas reservoirs}

4.3.3.1 Characteristics of “AD" tight gas reservoirs Conventional tight reservoirs form through the compaction and densification of conventional reservoirs, and they often show accumulation in zones of relatively high porosity and permeability. With the exception of relatively low porosity and permeability, there is no obvious distinction between conventional tight and conventional reservoirs.

Therefore, conventional tight reservoirs are characterized by: distribution in structurally high areas; partial enrichment in zones of relatively high porosity and permeability; no direct connection between sources and reservoirs; overlaying cap rocks that play a significant role in sealing processes; a uniform gas-water interface; higher inner pressure than hydrostatic pressure under a stable state; continuously high pressure; and relatively small distribution areas and reserve scales. By trap type, conventional tight reservoirs can be subdivided into anticlinal tight gas reservoirs, fault block tight gas reservoirs, lithological tight gas reservoirs, and stratigraphic tight gas reservoirs (Pang et al. 2014).

\subsubsection{Characteristics of "DA" tight gas reser-} voirs Unlike conventional and conventional tight reservoirs, deep tight gas reservoirs are characterized by the following features: close contact between source rocks and reservoirs; continuous widespread distribution; the presence of relatively deep depressions or sags and slope belts with large distribution areas (as buoyancy and cap rocks no longer determine natural gas accumulation processes); low well production but relatively large reserves; the absence of a uniform gas-water interface that can cause gas-water inversion; and pressure lower than stable-state hydrostatic pressure, showing stable low pressure anomalies (Jiang et al. 2006; Pang et al. 2014).

\subsubsection{Characteristics of composite tight gas reser-} voirs Composite tight gas reservoirs are characterized by the following features: the accumulation of tight gas in structurally high and low areas; the accumulation of tight gas within sweet spots that are also gas-bearing in tight sandstone regions; gas-bearing properties within sand bodies that connect to the source regions; and high and low pressure anomalies within tight gas reservoir formation. Therefore, composite tight gas reservoirs are distributed widely, are not constrained by structural and trap conditions, and exhibit gas-bearing properties and enormous reserves but with complex gas-water distribution and no clear edge or bottom water areas. Hydrocarbon accumulation and preservation also significantly depend on subsequent tectonic movement processes (Pang et al. 2013, 2014).

\section{Controlling factors and development models of tight sandstone gas reservoirs}

\subsection{Controlling factors and development models of "AD" tight sandstone gas reservoirs}

Conventional tight gas reservoirs are formed from conventional gas reservoirs that experience subsequent densification due to compaction and diagenesis. Their formation 
mechanisms and distribution characteristics resemble those of conventional gas reservoirs. When gas accumulates, reservoirs have not yet been densified, i.e., gas charging and accumulation is completed in conventional gas reservoirs. Densification then occurs due to subsequent burial compaction and structural compression (Jiang et al. 2006). The development and distribution of "AD" tight sandstone gas reservoirs are mainly controlled by source kitchens (S), regional overlaying cap rocks (C), gas reservoirs (D) and low fluid potential areas $(\mathrm{P})$, with the development model shown by "T-CDPS" (T means time). The spatiotemporal combination of these functional elements controls gas reservoir formation and distribution, and low fluid potential areas can be further divided into four sub-types: anticline $\left(\mathrm{P}_{1}\right)$, fault block $\left(\mathrm{P}_{2}\right)$, lithological $\left(\mathrm{P}_{3}\right)$, and stratigraphic $\left(\mathrm{P}_{4}\right)$ hydrocarbon reservoirs (Pang et al. 2012, 2014).

Conventional tight reservoirs develop prior to the reservoir densification period (RDP) and are characterized by two main stages (Fig. 8). Conventional gas reservoirs are formed during the first stage with buoyancy serving as the main accumulation force, while reservoir densification occurs during the second stage as a result of burial compaction, structural compression, and cementation. Groundwater circulation ceases after hydrocarbon charging, which results in the disturbance of chemical equilibrium and in the deceleration of cementation. However, natural gas charging has no effect on compaction, so compaction acts as the most important factor for reservoir densification. "Four high, two small, and one separation" principles are thus used as discriminant criteria of conventional tight gas reservoirs. "Four high" denotes hydrocarbon accumulation and sealing in structurally high positions, enrichment in zones of relatively high porosity and permeability, and high pressure reservoir formation. "Two small" denotes a small distribution area and small reserve scale. "One separation" denotes a general

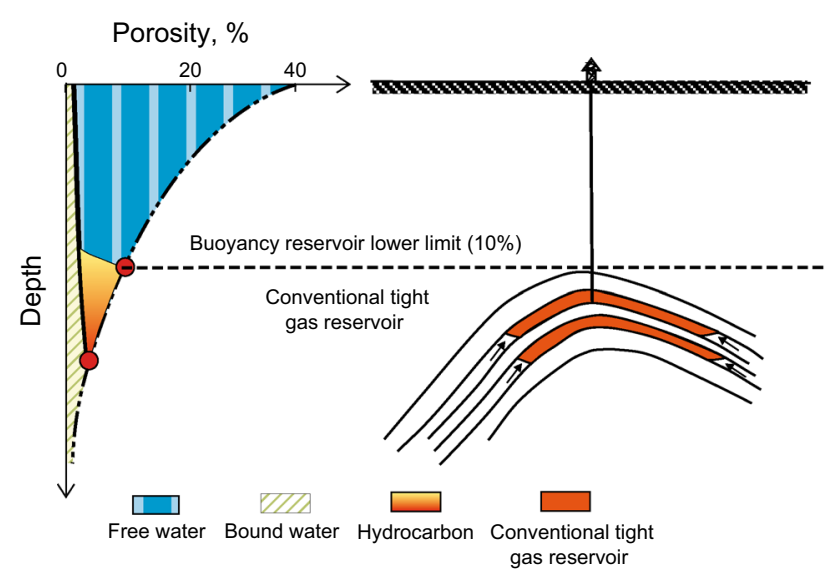

Fig. 8 Accumulation mechanisms and distribution features of conventional tight gas reservoirs (Pang et al. 2013) separation between sources and reservoirs, i.e., no direct connection between them (Pang et al. 2014).

\subsection{Controlling factors and development models of "DA" tight sandstone gas reservoirs}

Unlike conventional reservoirs, deep tight gas reservoirs are always found in structurally low areas (e.g., slopes of deep depressions or basins). "DA" deep tight gas forms after reservoir densification. Large quantities of gas expelled by effective source rocks migrates directly into adjacent tight reservoirs under the decisive force of hydrocarbon molecular expansive force (not buoyancy). Pore water is drained to extend the gas distribution area which is then aggregated to form large and continuously distributed tight deep gas reservoirs (Fig. 9). Deep tight gas reservoirs are mainly controlled by effective source rocks positioned adjacent to reservoirs $(S)$ and characterized by continuous hydrocarbon expulsion, widely distributed reservoirs (D), stable tectonic settings (W), and universal reservoir densification (L), with the development model shown by "T-LWDS" (T means time). A stable tectonic setting is conducive to the preservation of deep tight gas reservoirs, and widely distributed and universally densified reservoirs promote the short-distance accumulation of natural gas and the displacement of pore water. Source rocks with continuous gas supplies also serve as a solid material base for the development and distribution of deep tight gas reservoirs. Spatiotemporal configuration of these four functional elements determines the timing and depth of deep tight gas reservoir development.

With reservoirs in deep depressions first reach the lower limit of buoyancy accumulation, deep tight gas reservoirs first form in deep depressions and gradually extend outward (Song et al. 2013). Deep tight gas reservoirs have

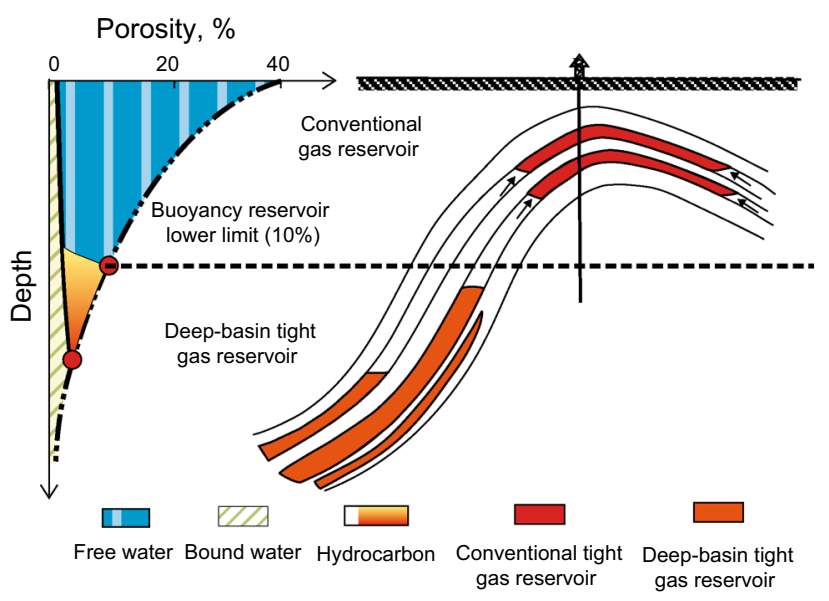

Fig. 9 Accumulation mechanisms and distribution features of deep tight gas reservoirs (Pang et al. 2013) 
always expanded symmetrically from central areas of depressions (e.g., gas reservoirs in the Red Desert Basin of Wyoming and in the San Juan Basin of New Mexico, USA), from foreland lateral margin slopes (e.g., gas reservoirs in Elmworth of Alberta, Canada and in the Green River Basin of Wyoming, USA), and from structural slope belts (e.g., Milk River gas reservoirs in Alberta, Canada and Clinton sandstone gas reservoirs in the Appalachian Basin of eastern Ohio, USA). "Four low, two large, and one close contact" principles are thus used as discriminant criteria for deep tight gas reservoirs. "Four low" denotes hydrocarbon accumulation and inversion in structurally low positions, enrichment in zones of relatively low porosity and permeability, and stable reservoir formation under low pressure. "Two large" denotes large distribution area and large reserve scale. "One close contact" denotes close contact between source rocks and reservoirs (Pang et al. 2014).

\subsection{Controlling factors and development models of composite tight gas reservoirs}

Composite tight gas reservoirs that exhibit the composite features of conventional tight gas reservoirs and deep tight gas reservoirs are controlled by buoyancy and hydrocarbon molecular expansive force during the early and late accumulation stages, respectively. The main controlling factors of composite tight gas reservoir accumulation can thus be classified into two subsidiary sets. One set is associated with the accumulation of conventional tight gas reservoirs, mainly cap rocks (C), gas reservoirs (D), low fluid potential areas $(\mathrm{P})$, and source kitchens $(\mathrm{S})$. The other is associated with deep tight gas reservoirs, mainly universal reservoir densification (L), stable tectonic settings (W), widely distributed reservoirs (D), and source rocks in a close contact with reservoirs (S). Therefore, we infer that the development of composite tight gas reservoirs is driven by the following six main factors $\mathrm{S}, \mathrm{D}, \mathrm{C}, \mathrm{W}, \mathrm{P}$, and $\mathrm{L}$, with the accumulation process depending on the spatiotemporal combination of these functional elements, and with the development model shown by "T-CDPS + T-LWDS" (Pang et al. 2014). The genetic mechanisms of composite tight gas reservoirs are thus a recombination of conventional tight and deep tight gas reservoir accumulations, resulting in the complex gas-water relationships and full gas-bearing properties.

Composite tight gas reservoirs are distributed widely in anticline belts, deep depressions, and slope zones as a result of superimposition of conventional and deep tight gas reservoirs in deep basins, also including buoyancyadjusted deep tight gas reservoirs reconstructed through subsequent fault or fracture development (e.g., subsequent inner-sag uplifting). Gas charging and accumulation processes are based on early buoyancy and then later on molecular expansive force. Composite tight gas reservoirs are formed through accumulation followed by densification and re-accumulation, and two genetic mechanisms can be identified. Driven by the first mechanism, conventional tight and deep tight gas reservoirs of the same depth form before and after reservoir densification, respectively. Given the order of gas accumulation processes, composite tight gas reservoirs are superimposed by different reservoir types following a period of multi-phase hydrocarbon expulsion. The other mechanism refers to partial uplifting in deep tight gas reservoirs induced by subsequent tectonic adjustments and improved reservoir physical properties close to those of conventional reservoirs (low porosity and high permeability) as a result of fault and fracture reconstruction. Buoyancy then occurs again, changing partial gas-water distribution and maintaining large gas-bearing areas in deep tight gas reservoirs, ultimately leading to the development of composite tight gas reservoirs of an adjusted genesis (Pang et al. 2013, 2014).

Three stages of composite tight gas reservoir formation are identified (Fig. 10). Conventional gas reservoirs always develop during the first stage (i.e., anticlinal, stratigraphic, and lithological gas reservoirs). Deep tight gas reservoirs form at the same time as or after the accumulation of conventional gas reservoirs during the second stage and are mainly distributed in depositional centers, slope belts, or marginal areas of deep basins. During the third stage, conventional gas reservoirs are transformed into conventional tight reservoirs with increasing the burial depth, and gas-bearing areas of deep tight gas reservoirs expand continuously, resulting in the final formation of composite tight gas reservoirs (Pang et al. 2014).

"Four high, four low, two large and one close contact" principles are used as discriminant criteria for composite tight gas reservoirs. "Four high and four low" denotes hydrocarbon accumulation in structurally high and low positions, enrichment in zones of both high and low porosity, high- and low-yield hydrocarbon bed development, and hydrocarbon beds found in high and low pressure settings. "Two large" denotes large distribution areas and reserve scale. "One close contact" denotes a close contact between source rocks and targeted reservoirs.

\section{Resource potential of tight sandstone gas reservoirs}

\subsection{Resource potential of tight sandstone gas reservoirs worldwide}

As a major exploration field of unconventional natural gas resources, tight sandstone gas shows great resource potential, and it is found around the world. According to 


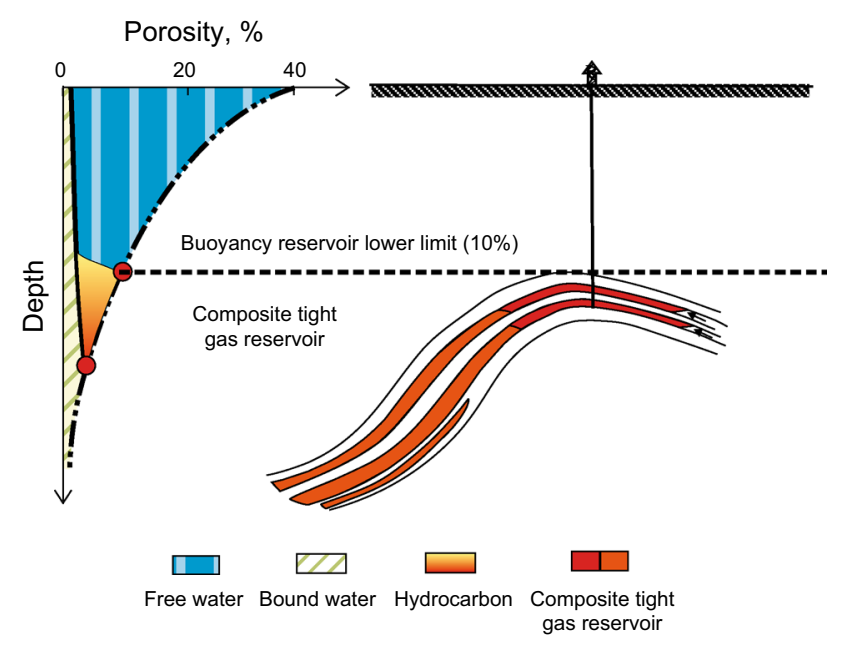

Fig. 10 Accumulation mechanisms and distribution features of composite tight gas reservoirs (Pang et al. 2013)

the USGS, roughly 70 tight sandstone gas reservoir basins have been identified around the world, and most are located in the Asia-Pacific region, North America, Latin America, the former Soviet Union, the Middle East, and North Africa, with geological reserves totaling $210 \times 10^{12} \mathrm{~m}^{3}$. Of this total, the Asia-Pacific region, North America, and Latin America account for $51.0 \times 10^{12}, 38.8 \times 10^{12}$, and $36.6 \times 10^{12} \mathrm{~m}^{3}$, thus accounting for roughly $60 \%$ of global tight gas reserves (IEA 2009).

Recently, numerous scholars have focused on recalculating global geological reserves of tight sandstone gas, which are significantly larger than the estimations presented above. Resource appraisals drawn from the Institut Français du Pétrole (IFP) show that tight gas reserves in the USA and Canada are $(402-442) \times 10^{12} \mathrm{~m}^{3}$, and global total reserves amount to $(310-510) \times 10^{12} \mathrm{~m}^{3}$ (Yang et al. 2012). Aguilera (2008) reported technical recoverable reserves of global tight sandstone gas of $428 \times 10^{12} \mathrm{~m}^{3}$, which roughly corresponds to the volume of conventional natural gas reserves (Qiu and Deng 2012). The resource potential of tight gas all over the world is thus evident.

\subsection{Resource potential of tight sandstone gas reservoirs in China}

\subsubsection{Advantageous forming conditions of tight gas reservoirs in China}

Based on the material basis, reservoir genesis, sourcereservoir contact, and accumulation features of tight sandstone gas, the geological settings found in China favor the development of large-scale tight sandstone gas fields.

6.2.1.1 Major coal-measure source rocks Coal series are well developed in sedimentary basins of China, and three major coal-forming periods have been identified: the Late Paleozoic, Mesozoic, and Cenozoic (Li et al. 2012). The northern and southern China areas, respectively, include the Carboniferous-Permian series of the Ordos Basin and the Upper Permian Longtan and Changxing Formations, which developed during the Late Paleozoic, and the LowerMiddle Jurassic Yan'an Formation and Upper Triassic Xujiahe Formation in the Sichuan Basin that developed during the Mesozoic (the Lower Cretaceous Yingcheng Formation is referred to as coal-bearing series in fault basins of eastern China). Cenozoic coal-forming basins are mainly found along the west side of the Pacific and along the Neo-Tethys ocean shore.

Coal-measure source rocks are widely distributed in the Sulige gas field of the Ordos Basin, in the Xujiahe Formation of the central Sichuan Basin, and in the Kuqa gasbearing areas of the Northern Tarim Basin. Coal-measure source rocks from the Taiyuan and Shanxi Formations of sea-land transitional facies in the Ordos Basin have a depositional area of approximately $13.8 \times 10^{4} \mathrm{~km}^{2}$ that is characterized by coal layers and dark mudstones with a thickness of 10-14 m, TOC content of around $63 \%$, and hydrocarbon generation intensity of $15 \times 10^{8} \mathrm{~m}^{3} / \mathrm{km}^{2}$, serving as a favorable setting for the development of largeto medium-sized gas fields. Coal-measure series, as favorable source rocks, are mainly characterized by type III organic matter, high levels of abundance, gas generation capacities during highly thermal evolution phases, and sheet-like hydrocarbon generation and continuous charging. Carbon isotope diagrams presented by Dai et al. (2012) also show that all tight sandstone gas in China is coalderived, supporting the fact of coal-measure source rocks as a favorable material basis.

6.2.1.2 Widely distributed tight reservoirs Tight reservoirs in China are mainly characterized by large distribution areas, deep burial depth, complex diagenetic evolutionary patterns, poor physical properties, significant heterogeneity, non-Darcy seepage migration patterns, and non-buoyancy accumulation. Continental hydrocarbon exploration efforts conducted in China show that widespread, multi-genetic sand bodies are well developed in the middle of large-scale lacustrine basins, thus acting as the most important prospecting targets for continental lithological hydrocarbon reservoirs (Li et al. 2012). Central sand bodies are considered to originate from shallow deltas and sandy debris flows, and their formation conditions, microfacies composition, distribution models, and genetic classification are still poorly understood. Shallow meandering channel deltas are well developed in modern lacustrine basins of China. The Ordos Basin underwent a denudation period that lasted over $100 \mathrm{Ma}$ during the Caledonian, and a general flattening of topography in the 
Late Paleozoic resulted in a small thickness difference of less than $30 \mathrm{~m}$ in the 8 th member of the Shihezi Formation. This gentle delta with a slope obliquity of $<1^{\circ}$ favors the accumulation of slope-type tight sandstone gas reservoirs.

Tight reservoirs in large Chinese basins are mainly characterized by deep burial and intense compaction processes followed by densification as a result of structural compression and cementation. Natural gas develops as free gas within the micro-nano pore structures (Zhu et al. 2013), with diameters ranging from 0.03 to $2 \mu \mathrm{m}$.

In summary, tight sandstone gas reservoirs in China are characterized by sheet-like coal-measure source kitchens, widely distributed reservoirs, a close contact between source rocks and reservoirs, and 3D gas-bearing and partial accumulation. They are mainly found in the Ordos, Sichuan, Tarim, Bohai Gulf (deep zone), Qaidam, Songliao, southern Junggar, Chuxiong, and East China Sea Basins.

\subsubsection{The promising potential of tight sandstone gas in China}

Tight gas with considerable resource potential is widely distributed in petroliferous basins across China. Recent tight gas exploration efforts in China have developed rapidly, representing major fields of natural gas discovery and production. In addition to large tight gas fields found in the Upper Paleozoic of the Ordos Basin, in the Xujiahe Formation of the Sichuan Basin, and in the Kuqa deep depression of the Tarim Basin, a series of tight gas reservoirs has been recently found in the Turpan-Hami, Songliao, and Bohai Gulf Basins. Tight gas in China, which is ample and has excellent resource prospect, has been identified as the most feasible alternative unconventional natural gas resource.

The newly found proven reserves of tight gas are up to $3110 \times 10^{8} \mathrm{~m}^{3}$ each year, accounting for roughly $52 \%$ of total discovered natural gas reserves in the same period (Zou et al. 2014). By the end of 2011, the proven total reserves of tight gas in China reached $3.3 \times 10^{12} \mathrm{~m}^{3}$, roughly accounting for $39 \%$ of total natural gas reserves, in which $96 \%$ of the proven reserves of tight sandstone gas are from the Ordos and Sichuan Basins. The Sulige gas field, as the largest tight gas-bearing area, has proven geological reserves of $3.5 \times 10^{12} \mathrm{~m}^{3}$ and annual production of $169 \times 10^{8} \mathrm{~m}^{3}$ (Zou et al. 2013). Tight gas resources yielded a total production of approximately $256 \times 10^{8} \mathrm{~m}^{3}$ in 2011, accounting for nearly one-fourth of total natural gas production, with annual production in the largest Sulige gas field exceeding $137 \times 10^{8} \mathrm{~m}^{3}$. Given the supplies and prospects of tight sandstone gas in China, we predict that the natural gas production will increase continuously and rapidly, which should reach $600 \times 10^{8} \mathrm{~m}^{3}$ by $2020(\mathrm{Li}$ et al. 2012).

The resource evaluations of tight gas in China based on analog methods have shown widespread distribution of tight sandstone gas reservoirs. The favorable continental basin areas are roughly $32 \times 10^{4} \mathrm{~km}^{2}$, geological reserves are roughly $(17.4-23.8) \times 10^{12} \mathrm{~m}^{3}$, and recoverable resources are roughly $(8.8-12.1) \times 10^{12} \mathrm{~m}^{3}$ (Jia et al. 2012). As feasible tight gas exploration areas, the Upper Paleozoic series of the Ordos Basin, the Upper Triassic Xujiahe Formation of the Sichuan Basin, and the Kuqa deep depression of the Tarim Basin were, respectively, found to have reserves of $(5.9-8.15) \times 10^{12}$, $(4.3-5.7) \times 10^{12}$, and $(2.7-3.4) \times 10^{12} \mathrm{~m}^{3}$. We also identified four other potential target areas: the Lower Cretaceous Denglouku Formation of the Songliao Basin, the third and fourth members of the Paleogene Shahejie Formation of the Bohai Gulf Basin, the Jurassic series of the Turpan-Hami Basin, and the Permian and Jurassic series along the southern margin of the Junggar Basin.

Thus, tight sandstone gas reserves in China show considerable resource potential, which motivated natural gas exploration and production efforts in China, and tight sandstone gas plays a key role in the natural gas industry.

\subsubsection{Tight sandstone gas distributed in basins of central and western China}

Tight gas reservoirs are distributed widely across China and are mainly found in central and western regions of China (Wang 2002). The Ordos, Sichuan, and Tarim Basins are proven tight gas-bearing basins with considerable resource potential, with proven total reserves of roughly $3.6 \times 10^{12} \mathrm{~m}^{3}$, accounting for $40 \%$ of natural gas proven reserves in China. The Junggar and Turpan-Hami Basins are also favorable areas.

Tight gas exploration in the Ordos Basin began in the late 1980s, and nine gas fields have been discovered. There are five gas-bearing reservoir-cap rock assemblages, and the average porosity and permeability are $4 \%-8 \%$ and $(0.5-1) \times 10^{-3} \mu \mathrm{m}^{2}$, respectively. The gas-bearing areas of tight sandstone gas cover approximately $10 \times 10^{4} \mathrm{~km}^{2}$ and the geological reserves of $50 \times 10^{12} \mathrm{~m}^{3}$, accounting for over $90 \%$ of the basin total reserves. The Upper Paleozoic Shihezi, Shanxi, and Taiyuan Formations are the major gas production series in the Sulige, Daniudi, Wushenqi, Shenmu, and Mizhi large-scale tight gas fields, with proven reserves exceeding $1 \times 10^{11} \mathrm{~m}^{3}$. The Sulige gas field has proven reserves of $2.85 \times 10^{12} \mathrm{~m}^{3}$ and has shown a rapid increase in production. In 2010, the gas production in the Sulige and Daniudi fields increased to $106 \times 10^{8}$ and $22.8 \times 10^{8} \mathrm{~m}^{3}$, respectively, and those are 
expected to reach $230 \times 10^{8}$ and $35 \times 10^{8} \mathrm{~m}^{3}$, respectively, by 2020 .

Tight gas reservoirs in the Sichuan Basin are mainly found in the western depression and central zones, with the average porosity and permeability of $1.2 \%-13.2 \%$ and $(0.01-0.82) \times$ $10^{-3} \mu \mathrm{m}^{2}$, respectively, in the tight sandstone reservoir of the Upper Triassic Xujiahe Formation, and with total geological reserves estimated at $26 \times 10^{12} \mathrm{~m}^{3}$. The Guang' an, Hechuan, and Anyue gas fields with proven reserves exceeding $1 \times 10^{11} \mathrm{~m}^{3}$ were also discovered in the central zone and are characterized by poor physical properties of the Upper Triassic Xujiahe Formation evidenced by porosity and permeability of $6 \%-10 \%$ and $(0.1-5) \times 10^{-3} \mu \mathrm{m}^{2}$, respectively. Tight gas reservoirs in the central zone yield lower proven reserves than those of the Sulige gas field, which are $0.5 \times 10^{12} \mathrm{~m}^{3}$, and annual production of $12 \times 10^{8}$ and $15 \times 10^{8} \mathrm{~m}^{3}$ was recorded for 2010 and 2011, respectively. Those are expected to reach $60 \times 10^{8} \mathrm{~m}^{3}$ by 2020 .

Tight sandstone gas in China presents great resource potential and is inferred to be the most feasible unconventional gas sources and an important component of the natural gas industry with the development of exploration theories and techniques. Tight gas exploration can now guide future unconventional natural gas exploration and production in China (Dai et al. 2012).

\section{Conclusions}

(1) Tight gas reservoirs, as a typical unconventional natural gas resource, are characterized by reservoir porosity of $<10 \%$, in situ permeability of $<0.1 \times$ $10^{-3} \mu \mathrm{m}^{2}$ (air permeability $<1.0 \times 10^{-3} \mu \mathrm{m}^{2}$ ), superimposed and widespread distribution, sheet-like coal-measure source rocks, continuous hydrocarbon generation, adjacent source rocks and reservoirs, vertical migration across short distances, complex gas-water relationships that are not controlled by structural contours, an absence of uniform gas-water interface and pressure system, high or low pressure anomalies, large-scale distribution area in structurally high positions, deep depressions, core areas of synclines, and downdip regions in structural slope belts, high resource potential, and partial accumulation controlled by sweet spots and fractures.

(2) Water and gas inversion processes were detected by capillary glass tube and quartz sand modeling experiments, and critical geological conditions without buoyancy-driven mechanism can thus be proved. In light of the relationship between gas charging and reservoir densification periods during tight gas accumulation processes, we propose the following genetic classification: (a) "first accumulation then reservoir densification" conventional tight gas reservoirs, (b) "first reservoir densification then accumulation" deep tight gas reservoirs, and (c) composite tight gas reservoirs.

(3) "Accumulation-densification" gas charging occurs prior to reservoir densification, accumulating in structurally high positions under the action of buoyancy with the following main controlling factors, source kitchens (S), regional overlaying cap rocks (C), gas reservoirs (D), and low fluid potential areas (P). "Densification-accumulation" tight gas forms after reservoir densification under hydrocarbon generation expansive force (no buoyancy), and accumulates in depression and slope areas with the following controlling factors, effective source rocks (S), widely distributed reservoirs (D), stable tectonic settings (W), and universal reservoir densification (L). Composite tight gas reservoirs exhibiting features of both conventional tight gas and deep tight gas reservoirs are controlled by buoyancy and hydrocarbon molecular expansive force during the early and late accumulation phases, respectively, with the following main controlling factors, source kitchens (S), reservoirs (D), cap rocks (C), stable tectonic settings (W), low fluid potential areas (P), and universal reservoir densification (L), and are widely distributed in anticline belts, deep depressions, and slope areas. (4) Tight sandstone gas, as an important unconventional natural gas resource, shows great resource potential and is widely distributed around the world with geological reserves reaching $210 \times 10^{12} \mathrm{~m}^{3}$. Based on the material basis, reservoir genesis, sourcereservoir contact relations, and accumulation mechanisms of tight gas, we infer that tight gas in China exhibits favorable reservoir formation conditions and great resource potential. The tight gas resource is mainly found in the Ordos, Sichuan, Tarim, Junggar, and Turpan-Hami Basins of central-western China. This resource has promoted global unconventional natural gas exploration and production under existing technical conditions.

Acknowledgments This paper is supported by the National Natural Science Foundation of China (No. 41472112) and the National Major Projects (No. 2011ZX05018002).

Open Access This article is distributed under the terms of the Creative Commons Attribution 4.0 International License (http://crea tivecommons.org/licenses/by/4.0/), which permits unrestricted use, distribution, and reproduction in any medium, provided you give appropriate credit to the original author(s) and the source, provide a link to the Creative Commons license, and indicate if changes were made. 


\section{References}

Aguilera R. Role of natural fractures and slot porosity on tight gas sands. In: SPE Unconventional Reservoirs Conference. 10-12 Feb, Keystone, Colorado. 2008.

Chen G. Formation condition of synclinal hydrosealed gas pools in Qinshui Basin. Oil Gas Geol. 1998;19(4):302-6 (in Chinese).

Chen JY, Tan DQ, Yang CP. Advances in the research and exploration of unconventional petroleum systems. Geol Sci Technol Inf. 2003;22(4):55-9 (in Chinese).

Dai JX. Synclinal oil and gas pools. Acta Pet Sin. 1983;4(4):27-30 (in Chinese).

Dai JX, Ni YY, Wu XQ. Tight gas in China and its significance in exploration and exploitation. Pet Explor Dev. 2012;39(3): 257-65 (in Chinese).

Dai JX, Song Y, Zhang HF. The main controlling factors for the formation of large and middle sized gas reservoirs. Sci China Ser D. 1996;26(6):481-7 (in Chinese).

Dong XX, Mei LF, Quan YW, et al. Types of tight sand gas accumulation and its exploration prospect. Nat Gas Geosci. 2007;18(3):351-5 (in Chinese).

Gies RM. Case history for a major Alberta deep basin gas trap: the Cadomin Formation. In: Masters JA, editor. Case study of a deep basin gas field. AAPG Memoir 38. Tulsa: AAPG Bulletin; 1984. p. $115-40$.

Guan DS, Niu JY. China unconventional oil and gas geology. Beijing: Petroleum Industry Press; 1995. p. 12-40 (in Chinese)

Guo QL, Chen NS, Hu JW, et al. Geo-model of tight sandstone gas accumulation and quantitative simulation. Nat Gas Geosci. 2012;23(2):199-207 (in Chinese).

Holditch SA. Tight gas sands. J Pet Technol. 2006;58(6):86-93.

IEA. World Energy Outlook. 2013.

IEA. World Energy Outlook. 2009.

Jia CZ, Zheng M, Zhang YF. Unconventional hydrocarbon resources in China and the prospect of exploration and development. Pet Explor Dev. 2012;39(2):129-36 (in Chinese).

Jiang ZX, Lin SG, Pang XQ, et al. The comparison of two types of tight sand gas reservoir. Pet Geol Exp. 2006;28(3):210-4 (in Chinese)

Jiang ZX, Pang XQ, Zhang JC, et al. Summarization of deep basin gas studies. Adv Earth Sci. 2000;15(3):289-92 (in Chinese).

Jin ZZ, Zhang JC, Wang ZX. Some remarks on deep basin gas accumulation. Geol Rev. 2003;49(4):401-7 (in Chinese).

Law BE. Basin-centered gas systems. AAPG Bull. 2002;86(11): 1891-919.

Law BE, Dickinson WW. Conceptual model for origin of abnormally pressured gas accumulations in low-permeability reservoirs. AAPG Bull. 1985;69(8):1295-304.

Lei Q, Wan YJ, Li XZ, et al. A study on the development of tight gas reservoirs in the USA. Nat Gas Ind. 2010;30(1):45-8 (in Chinese)

Li JZ, Guo BC, Zheng M, et al. Main types, geological features and resource potential of tight sandstone gas in China. Nat Gas Geosci. 2012;23(4):607-15 (in Chinese).

Liang DG, Chen JP, Zhang BM. Continental hydrocarbon generation of the Kuqa depression in the Tarim Basin. Beijing: Petroleum Industry Press; 2004 (in Chinese).

Liu GY, Jin ZJ, Zhang LP. Simulation study on clastic rock diagenetic compaction. Acta Sedimentol Sin. 2006;24(3):407-13 (in Chinese)

Ma ZZ. Dynamic mechanisms and distribution models of deep tight sandstone gas reservoirs. Ph.D. Thesis. China University of Petroleum, Beijing. 2008 (in Chinese).

MacAvoy PW. Natural gas policy act of 1978. Washington: Federal Energy Regulatory Commission; 1978.
Masters JA. Deep basin gas trap, western Canada. AAPG Bull. 1979;63(2):152-81.

National Energy Administration. Geological evaluating methods for tight sandstone gas. SY/T6832-2011. Beijing: Geological Publishing House; 2011 (in Chinese).

Nehring R. Growing and indispensable: the contribution of production from tight-gas sands to U.S. gas production. In: Cumella SP, Shanley KW, Camp WK, editors. Understanding, exploring, and developing tight-gas sands. 2005 Vail Hedberg Conference, vol. 3. Colorado: AAPG Hedberg Series; 2008. p. 5-12.

Pang XQ, Fang H, Tang LJ. Deep basin gas accumulation in the Ordos Basin. In: Fu CD, editor. Study of deep basin gas. Beijing: Petroleum Industry Press; 2001. p. 65-73 (in Chinese).

Pang XQ, Jiang ZX, Huang HD, et al. Formation mechanisms, distribution models, and prediction of superimposed continuous hydrocarbon reservoirs. Acta Pet Sin. 2014;35(5):795-828 (in Chinese).

Pang XQ, Jin ZJ, Jiang ZX, et al. Critical condition for gas accumulation in the deep basin trap and physical modeling. Nat Gas Geosci. 2003;14(3):207-14 (in Chinese).

Pang XQ, Zhou XY, Dong YX, et al. Formation mechanism classification of tight sandstone hydrocarbon reservoirs in petroliferous basin and resources appraisal. J China Univ Pet. 2013;37(5):28-38 (in Chinese).

Pang XQ, Zhou XY, Jiang ZX, et al. Hydrocarbon reservoirs formation, evolution, prediction and evaluation in the superimposed basins. Acta Geol Sin. 2012;86(1):53-7 (in Chinese).

Qiu ZJ, Deng ST. Strategic position of unconventional natural gas resources in China. Nat Gas Ind. 2012;32(1):1-5 (in Chinese).

Rose PR, Everett JR, Merin IS. Possible basin centered gas accumulation, Raton Basin, Southern Colorado. Oil Gas J. 1984;82(40):190-7.

Schmoker JW. National assessment report of USA oil and gas resources. Reston: USGS; 1995.

Schmoker JW. Resource-assessment perspectives for unconventional gas systems. AAPG Bull. 2002;86(11):1993.

Schmoker JW. US Geological Survey assessment concepts for continuous petroleum accumulations. US Geol Surv. 2005;1:1-9.

Shou JF, Zhu GH, Zhang HL. Lateral structure compression and its influence on sandstone diagenesis - a case study from the Tarim Basin. Acta Sedimentol Sin. 2003;21(1):90-5 (in Chinese).

Song Y, Jiang L, Ma XZ. Formation and distribution characteristics of unconventional oil and gas reservoirs. J Palaeogeogr. 2013; 15(5):605-14 (in Chinese).

Spencer CW. Geologic aspects of tight gas reservoirs in the Rocky Mountain region. J Pet Technol. 1985;37(8):1308-14.

Spencer CW. Review of characteristics of low-permeability gas reservoirs in western United States. AAPG Bull. 1989;73(5): 613-29.

Surdam RC. A new paradigm for gas exploration in anomalously pressured "tight gas sands" in the Rocky Mountain Laramide basins (in seals, traps, and the petroleum system). AAPG Memoir. 1997;67:283-98.

Walls JD. Tight gas sands-permeability, pore structure, and clay. J Pet Technol. 1982;34(11):2707-14.

Wang T. Deep Basin gas fields in China. Beijing: Petroleum Industry Press; 2002. p. 3-71 (in Chinese).

Wang YC, Kong JX, Li HP, et al. Natural gas geology. Beijing: Petroleum Industry Press; 2004 (in Chinese).

Wang ZM. Formation mechanism and enrichment regularities of Kelasu subsalt deep large gas field in Kuqa Depression, Tarim Basin. Nat Gas Geosci. 2014;25(2):153-66 (in Chinese).

Wu HY, Liang XD, Xiang CF. Accumulation characteristics and mechanisms of synclines in the Songliao Basin. Sci China Ser D. 2007;37(2):185-91 (in Chinese). 
Wyman RE. Gas recovery from tight sands. SPE 13940. 1985.

Xiao ZH, Zhong NN, Huang ZL, et al. A study on hydrocarbon pooling conditions in tight sandstones through simulated experiments. Oil Gas Geol. 2008;29(6):721-5 (in Chinese).

Xie GJ, Jin ZJ, Yang LN. A numerical simulation on accumulation mechanism of deep basin gas. J China Univ Pet. 2004;28:13-7 (in Chinese).

Yang KM, Pang XQ. Developing mechanisms and detection methods of tight sandstone gas reservoirs: a case of the depression in the western Sichuan Basin. Beijing: Science Press; 2012 (in Chinese).

Yang SY, Zhang JC, Huang WD, et al. "Sweet spot" types of reservoirs and genesis of tight sandstone gas in Kekeya area, Turpan-Hami Basin. Acta Pet Sin. 2013;34(2):272-82 (in Chinese).

Yang T, Zhang GS, Liang K, et al. The exploration of global tight sandstone gas and forecast of the development tendency in China. Eng Sci. 2012;14(6):64-8 (in Chinese).

Yang XN, Zhang HL, Zhu GH. Formation mechanism and geological implication of tight sandstones: a case of Well YN-2 in Tarim Basin. Mar Orig Pet Geol. 2005;10(1):31-6 (in Chinese).

Yang XP, Zhao WZ, Zou CN, et al. Origin of low-permeability reservoir and distribution of favorable reservoir. Acta Pet Sin. 2007;28(4):57-61 (in Chinese).

Yuan ZW, Xu HZ, Wang BS, et al. Deep tight gas research in the Alberta Basin. Beijing: Petroleum Industry Press; 1996 (in Chinese).

Zeng JH. Experimental simulation of impacts of vertical heterogeneity on oil migration and accumulation in fining upwards sands. Pet Explor Dev. 2000;27(4):102-5 (in Chinese).

Zhang JC. Source-contacting gas: derived from deep basin gas or basin-centered gas. Nat Gas Ind. 2006;26(2):46-8 (in Chinese).

Zhang JC, Jin ZJ, Pang XQ. Formation conditions and internal features of deep basin gas accumulations. Explor Pet Geol. 2000;22(3):210-4 (in Chinese).

Zhang RH, Yao GS, Shou JF, et al. An integration porosity forecast model of deposition, diagenesis and structure. Pet Explor Dev. 2011;38(2):145-51 (in Chinese).
Zhao JZ, Fu JH, Yao JL, et al. Quasi-continuous accumulation model of large tight sandstone gas field in Ordos Basin. Acta Pet Sin. 2012;33(S1):37-52 (in Chinese).

Zhao WZ, Zou CN, Wang ZC, et al. The intension and signification of "sag-wide oil-bearing theory" in the hydrocarbon-rich depression with terrestrial origin. Pet Explor Dev. 2004;31(2):5-13 (in Chinese).

Zhou XY. Distribution regularities of natural gas in the Kuqa Foreland Basin. Beijing: Petroleum Industry Press; 2002 (in Chinese).

Zhu RK, Bai B, Cui JW, et al. Research advances of microstructure in unconventional tight oil and gas reservoirs. J Palaeogeogr. 2013;15(5):615-23 (in Chinese).

Zou CN, Tao SZ, Hou LH, et al. Unconventional petroleum geology. Beijing: Geological Publishing House; 2011a (in Chinese).

Zou CN, Yang Z, Zhang GS, et al. Conventional and unconventional petroleum "orderly accumulation": concept and practical significance. Pet Explor Dev. 2014;41(1):14-30 (in Chinese).

Zou CN, Zhang GS, Yang Z, et al. Geological concepts, characteristics, resource potential and key techniques of unconventional hydrocarbon: on unconventional petroleum geology. Pet Explor Dev. 2013;40(4):385-99 (in Chinese).

Zou CN, Zhang GY, Tao SZ, et al. Geological features, major discoveries and unconventional petroleum geology in the global petroleum exploration. Pet Explor Dev. 2010;37(2):129-45 (in Chinese).

Zou CN, Zhu RK, Bai B, et al. First discovery of nano-pore throat in oil and gas reservoir in China and its scientific value. Acta Pet Sin. 2011b;27(6):1857-64 (in Chinese).

Zou CN, Zhu RK, Wu ST, et al. Types, characteristics, genesis and prospects of conventional and unconventional hydrocarbon accumulations: taking tight oil and tight gas in China as an instance. Acta Pet Sin. 2012;33(2):173-87 (in Chinese). 